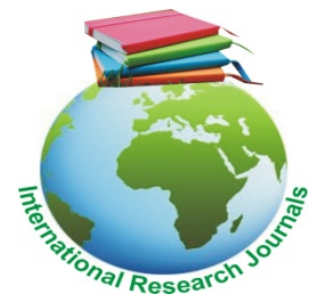

\title{
The link between routine diet, attention span and scholastic performance among grade 2 scholars in circuit one in Khomas Region, Namibia
}

\author{
Tjituri Elsie ${ }^{1}$, Amukugo Hans Justus $^{\star^{2}}$, Haoses-Gorases Lischen ${ }^{3}$ \\ School of Nursing, Faculty of Health, University of Namibia, Namibia \\ *Corresponding Author's E-mail: hamukugo@unam.na
}

\begin{abstract}
In Namibia, almost one out of every three children under the age of five is undernourished while one out of every $\mathbf{2 0}$ is obese. Thus, the concerns are nature and quality of Grade $\mathbf{2}$ scholars' routine diet; ability for sustained attention within a classroom setting should their routine diet fail to adequately provide sustained glucose and scholastic performance that may result from attention deficits due to presumed poor quality of routine diet. The purpose of this study was to determine and describe the link between routine diets, capacity for sustained attention span and scholastic performance among Grade 2 scholars in circuit one in Khomas region. The sampled population consisted of fifty seven (57) grade 2 scholars aged between 7-9 years from both Primary schools. The results showed no significant correlation as well as weak positive linear correlation between BMI percentile and likelihood of scholars giving attention in class $r(N=57)=0.116 p=0.389$. There was significant correlation as well as negative weak linear correlation between BMI percentile and arithmetic skill, $r(57)=-0.274, p=0.039$. Comparing scholars BMI percentile and reading skills showed no significant correlation as well as negative correlation between the scholars BMI percentile and reading skills, $r(57)=-0.025, p=0.851$. Comparing attention span and reading showed a significant and a moderate strong linear relationship between scholars' attention span and reading skills, $r(57)=0.59, p<0.001$. Whilst, there is significant and positive linear relationship between the scholars attention span and arithmetic skills, $r(57)=0.34, p=0.009$. Most scholars who participated in the study academically performed poorly in reading, arithmetic and psychometric tests despite majority of them having normal nutritional status. In conclusion, impairment of attention during lessons in classroom significantly contributed to poor performance in class and another contributing factor to poor academic performance can be associated with the classroom didactic).
\end{abstract}

Keywords: Diet, attention span, Scholarly performance and Scholars

\section{INTRODUCTION}

This descriptive study is firmly embedded in Public Health, with a focus on nutrition and public mental health/behavioral sciences as constituents to Public Health, collectively within the Ministry of Health and Social Services (MoHSS) of Namibia. 'Routine diet' refers to the habitual food intake or meal pattern of scholars, synonymous with usual pattern of food intake, customary food intake or regular food intake. The study assesses and describes the scholars focused food frequencies, while considering the main food groupings that a balanced routine diet should contain, as recommended daily allowance (RDA) per food grouping, referenced as Nutrient Reference Values (NRVs) for individuals four (4) years and older.

The American Dietetic Association (ADA, 2008) concluded that diet can affect cognitive performance in 
children. Nutrient composition and meal pattern can exert immediate and long-term beneficial or adverse effects on cognitive performance (Bellisle, 2004). Beneficial effects mainly result from a balanced diet, or from the correction of poor nutrition. Despite biological mechanisms that protect brain activity from disruption, some cognitive functions appear sensitive to short-term variations of glucose availability in certain brain areas (Bellisle, 2004). Glucose derived from glycemic carbohydrates (e.g. sugars and starches), fats and proteins acutely facilitates mental performance involved in demanding cognitive tasks that require sustained attention (Anding, 2010). From this literature, it transpires that the quality of scholars' routine diet links to attention.

Muris (2006) found that an attention control scale for children, such as the Connors Scale, was suitable for assessing subject's ability for sustained attention. The premise is that the rate of glucose metabolism, the immediacy of glucose availability to the brain after a meal, or depletion of glucose availability on skipping a meal, or an upsurge of glucose availability on excess intake of high glycemic index foods, links with ability for sustained attention (Anding, 2010). This baseline will enable the researcher to compile specific sub-groups according to routine food intake, e.g. those scholars who routinely skip breakfast, those scholars showing excess intake of glycemic carbohydrates (sugars and starches) and fats and proteins, and those scholars showing depletion of glycemic carbohydrates, fats and proteins due to deficient food intake however the causes of excessive and restricted food intake are not areas of interest in this study.

Since Grade 2 scholars need to pay sustained attention within a formal setting the research interest further focuses on whether the Grade 2 scholars' routine diet supports the demand for sustained attention. Availability of glycemic carbohydrates (as glucose availability to the brain), is closely associated with ability for sustained attention, with relatively immediate effects following intake thereof, and subject to the source of glycemic carbohydrates, effects could be more gradual (Anding, 2010), pending the Glycemic Carbohydrate Index of the particular source of food (Foster-Powell, Holt, and BrandMiller, 2002; Thomas, and Elliott, 2009). The glycemic index measures how quickly a person's blood sugar rises after ingestion of a particular carbohydrate food (FosterPowell, Holt, and Brand-Miller, 2002). This literature study urged the researcher to determine the link between routine diet and grade 2-scholars' ability for sustained attention, with resultant satisfactory or unsatisfactory scholastic performance - whichever applies. Professor Anding of Rice University, Department of Kinesiology in 2010 recommended a choice of four basic approaches to be followed when investigating routine diet' 'and nutritional planning, i.e. the anthropometric, the biochemical, the clinical and the dietary approaches (Anding, 2010).

The anthropometric approach involves taking body measurements of the subjects, i.e. measures of waist circumference, and measures of height and weight, with resultant computation of the subject's Body Mass Index (BMI), compared to ideal body weight indexes. The BMI greater than +1SD is considered overweight, greater than $+2 S D$, and less than -2SD thinness, while less than -3SD is severe thinness, (World Health Organization (WHO), 2010). Since this approach is non-invasive in nature, it is highly suitable for the current study. Physicians usually follow the biochemical approach, which involves blood sampling and biochemical analyses of blood cholesterol levels, iron status, hematocrit, hemoglobin and ferritin counts to identify malnutrition and/or over nutrition. The biochemical approach also considers the subject's vitamin D status, as well as the Mean Corpuscular Volume (MCV), where small red blood cells indicate possible iron deficiency. Large red blood cells suggest Vitamin B12 or folic acid deficiency. Further to the biochemical approach, urinalysis results can identify glucose or ketones in the urine, as well as urine concentration. High urine specific gravity indicates dehydration (Anding, 2010). Since this approach requires blood sampling it is considered invasive in nature, requiring specific skills and knowledge not applicable to this current study.

The clinical approach is also not suitable for this current study, since it involves an assessment of the subject's chronic illnesses, medications (prescription and over the counter), and dietary supplements (vitamins, minerals, herbal therapy). Chronic illnesses often require dietary modifications, while certain medications and dietary supplements can cause significant interactions and alter nutritional status (Anding, 2010). The fourth approach, i.e. the dietary approach, involves consideration of the results of a food and exercise diary and comparison of these results to an ideal caloric intake index (Anding, 2010). The dietary and anthropometric approaches are complimentary, therein that the subject's ideal body weight is multiplied by 10 to determine the subject's basal metabolic rate (BMR). The BMR gives an indication of what the subject's caloric intake is supposed to be, this index can identify whether the subject's caloric intake is too high or too low for daily maintenance of optimal functioning.

The dietary approach requires consideration of the child's growing status and activity level; hence children need more kilojoules than adults per kilogram of body weight because they are still growing, and when determining the BMR, $30 \%$ more kilojoules are added up if the subject is sedentary (inactive), $50 \%$ if moderately 
active and $100 \%$ if active. In the dietary approach, the mean food intake (i.e. carbohydrates, proteins, and fats) as well as the balance and quality of carbohydrates, proteins, and fats are compared against the preceding indexes to determine significant deviations (Anding, 2010). Doing so, specific patterns of malnutrition and/or over nutrition can be identified. Having studied research findings on the association between certain dietary patterns, sustained attention and cognitive performance (Muris, 2006; McArdle, Katch, andKatch, 2007), the further research interest focuses on Grade 2 scholastic performance, considering the findings published in the Namibia Alliance for Improved Nutrition report (NAFIN, 2010) that suggest malnutrition among Namibian children.

In Namibia, almost one out of every three children under the age of five was found undernourished, while one out of every twenty was found obese (NAFIN, 2010). By illustration, iron deficiency affects attention, learning ability, intellectual performance, stamina, and the mood of a child. According to the NAFIN report (2010), in some regions of Namibia iron deficiency affects one out of every two primary school children. Based on this report and other relevant literature, the researcher presumes that routine diet (viaglycaemic carbohydrate intake) will affect Grade 2 scholars' ability for sustained attention, with resultant effect on scholastic performance, as the impetus for this study.

\section{Overview of nutrition situation at the global level}

About one-third of children in the developing world are either underweight or stunted (low height for age) while more than 30 percent of the developing world's population suffers from micronutrient deficiencies, (MOHSS,2012).

The study done in South Africa shows the differences in under-nutrition between rural and urban populations, between gender as well as between ethnic groups. Two examples, stunting in children and underweight in men, illustrate this statement, (Vorster, 2010). A recent national study showed that $26.5 \%$ of South African children in rural areas were stunted compared to $16.7 \%$ in urban areas (Vorster, 2010). The South African demographic and health survey (1998) showed that while only $5 \%$ of white men were underweight with a body mass index (BMI) of less than $18.5 \mathrm{~kg} / \mathrm{m} 2,12.1 \%, 12.9 \%$ and $16.9 \%$ of coloured, black and Indian men respectively could be classified as being underweight (Vorster, 2010).

While South Africa is one of the countries in Africa with food and nutrition security at the national level even at the extend of exporting some of its food, many South Africans go hungry and are food insecure because of various issues such as affordability, as well as the distribution and accessibility of nutritious foods to meet their needs and this have led to relatively high prevalence rate of stunting among children and underweight among adult men, (Vorster, 2010). According to Food and Agriculture Organization (FAO) 1997, 2001a food security can be defined as the human right to be able to access safe, affordable and sufficient food to be well-nourished and lead to productive lives. Thus, food insecurity exists when people are unsure where their next meal will be coming from.

In Zambia several studies were done on both preschool and school aged children and these studies showed that malnutrition is a major problem in the country. During the last fifteen-years three national surveys documented the prevalence of malnutrition among preschool children: the 2007 Zambia Demographic Health Survey (ZDHS), the 2001-2002 ZDHS and the 1996 ZDHS (Central Statistics Office (CSO) et al., 2009, 2003, 1997 cited in Food Agriculture Organization (FAO), 2009). According to the most recent ZDHS conducted between April and October 2007, the prevalence of stunting among children under five years of age was $39 \%$, the prevalence of wasting was $5 \%$ with $1 \%$ severely wasting and that of underweight was estimated at $19 \%$ (CSO et al., 2009 cited in FAO, 2009).

While at the national level, overall $39 \%$ of children under five were stunted and $16 \%$ were severely stunted. These studies showed that the prevalence of stunting increased rapidly with age. At age $0-6$ months, $12 \%$ of the children were stunted, probably as a consequence of intrauterine growth retardation and/or prematurity. Prevalence increased during the first year of life and peaked at $49 \%$ in the age group 12-23 months. After 2 years of age, the prevalence of stunting remained very high (> 40\%) (CSO et al., 2009 cited in FAO, 2009). Inadequate infant and young child feeding practices, coupled with high rates of infectious diseases and inadequate access to health care, are the principal proximate causes of the deterioration of the nutritional status after 6 months of age. The prevalence of stunting was significantly higher among children living in rural areas (42\%) when compared to those living in urban areas (33\%) while for wasting there was no significant difference between urban and rural areas; in urban area it was (4\%) while rural area it was (5\%). Regional variations in prevalence were substantial: prevalence was the highest in Luapula with (50\%), and lowest in the Southern province with (30\%) (CSO et al., 2009 cited in FAO, 2009).

Additionally, the Mother's education was found to be linked to nutritional status of children, although the magnitude of this effect was not large: the prevalence of stunting was $38 \%$ among children of mothers with no 
education while it was $32 \%$ among children of mothers with secondary or higher education. However, according to CSO et al., 2009 cited in (FAO, 2009) the educational level of the mother should not be interpreted as the direct link to stunting as there are confounding variables that can add the value to the nutritional status of the child.

According to (CSO and ORC Macro, 2003 cited in FAO, 2009) the 2002 Zambia DHS EdData Survey (ZDES), conducted between August and October 2002, was the first education survey of its kind in Zambia. This survey was representative at national level and the sample included all the 2001-2002 Zambia DHS households with children in the eligible child age range. The survey collected and analysed height and weight measurements for 2624 children age 7-9.99 years. This study indicated that overall $31 \%$ of school-age children (age 7-9.99) were stunted and 9\% were severely stunted. Differentials in the prevalence of stunting by gender were significant: $35 \%$ of boys were stunted versus $26 \%$ of girls. As the case in South Africa children living in rural areas were twice as likely to be stunted as those living in urban areas. The prevalence of stunting was highest in Luapua (51\%) and Northern (50\%) provinces. Prevalence of stunting was considerably higher among children who had never attended school (49\%) or who had attended only pre-primary school (43\%) than among children who had attended primary school (23\%). However, this information should not be interpreted as education has the direct link to stunting as the children who are attending schools are in the favourable socio-economic environment as most schools have feeding programmes.

The same study showed that the prevalence of underweight among school-age children was $17 \%$ in 2002. For boys living in rural areas and those living in Luapula and Northern provinces were more likely to be underweight. The prevalence of underweight was also significantly higher among children who had never attended school when compared to those who had attended at least pre-primary school (CSO and ORC Macro, 2003 cited in FAO, 2009).

According to the study done in China rural area the prevalence of stunting among children in the surveillance sites was $>40 \%$ over the study period, with a prevalence of severe stunting (below-3 Standard Deviation (SD)) from the international reference median value) of around 14\%, (Chang Ying et al, 2003). This prevalence was considerably higher than the national average for China (32\% below-2 SD of the international reference median value) and also higher than the national average for rural areas (36\%), as estimated in the 1987 national grow survey. Consequently like in South Africa and Zambia the prevalence vary from one province to another in China the stunting prevalence was highest $(>50 \%)$ in the study areas in Guizou, Hunan and Guangdong and lowest
(23\%) in Hubei.

While the prevalence of low weight-for-age among the surveyed children was $24-28 \%$ for all study years which is higher than the national average for China (21.3\%) and also somewhat higher than the average for rural areas (23.7\%) (25); also the prevalence of children <-3 SD of the median of the international reference population was about 4\%, (Ying, Fengying, Wenjun, Keyou, Daxun, andOnis, 2003). Moreover, like for the stunting there was a significant difference of underweight across different provinces for example the Guizhou had the highest prevalence of underweight, followed by Hunan and Guangdong, with prevalence above $30 \%$. While, the lowest prevalence underweight (12.7\%) was in Hubei province.

The study done in Nigeria at Ekiti schools showed that children recorded to be malnourished were higher $(49.4 \%)$ followed by normal children $(45.5 \%)$ whereas overweight and obese were (13.7\%) and (0.5\%) respectively, (Adegun, Ajayi-Vincent, andAlebiosu, 2013).

Additionally, there was a significant difference between the nutritional status of pupil at the public school and private school in Ekiti. The pupils selected from the privately owned primary schools had higher nutritional status with a mean of $16.66+2.36 \mathrm{~kg}$ compared to those in public primary schools with a mean of $15.46+3.10 \mathrm{~kg}$. The calculated t-value of 3.919 was found to be higher and greater than the table t-value of 1.980 at 0.05 level of significance. This result shows that there is a significant difference in the nutritional status of children in public and private owned primary schools in Ekiti State, (Ying, Fengying, Wenjun, Keyou, Daxun, andOnis, 2003).

All the above mentioned studies in different countries showed a common trend of malnutrition, stunting or underweight. The nutritional status is influenced by longterm dietary inadequacy, recurrent illness and is notably associated with increasing chronic food insecurity, limited access to health care, and high poverty levels, high disease burden exacerbated by the HIVIAIDS pandemic, lack of sanitation and poor access to quality nutrition, (FAO, 2009; Adegun, Ajayi-Vincent, andAlebiosu, 2013; Vorster, 2010; Ying, Fengying, Wenjun, Keyou, Daxun, andOnis, 2003).

Additionally, as observed across all the studies done in different countries the high prevalence of stunting observed across school-age children can be related to the high prevalence of stunting observed among preschool children as the potential for catch-up growth among stunted children is thought to be limited after the age two years, particularly when the children remain in disadvantaged environments, (FAO, 2009; Adegun, AjayiVincent, andAlebiosu, 2013; Vorster, 2010; Ying, Fengying, Wenjun, Keyou, Daxun, andOnis, 2003). 


\section{Overview of nutrition situation in namibia}

Malnutrition remains a public health problem in Namibia since almost one out of every three children under the age of five is malnourished, (NAFIN, 2010). Additionally, the percentage of underweight children (too thin for age) has declined in the last two decades stunting (too short for age) and wasting (too thin for height) has increased drastically despite the economic growth experienced by the country which led it to be classified as an upper middle income country. Nevertheless, despite the tremendous economic growth experienced by the country the wealth did not benefit the individuals on the ground.

According to (NAFIN, 2010) the geographical general pattern in Namibia indicates that the regions with high levels of poverty, low literacy rates, high HIVIAIDS prevalence rate and with predominantly rural populations have the highest levels of stunting ranging from $39 \%$ in Kavango, Hardap, Ohangwena to $22 \%$ in Khomas, Erongo and Omaheke to mention the few. Moreover, children born in the poorest and second poorest wealth quintile households have a three-fold risk of being stunted compared to those born in the richest quintile.

Consequently, approximately four percentages of the children were found to be overweight or obese. This overnutrition was more persistent in urban settings compared to rural settings (7 percent compare to 3 percent in rural areas) and in wealthier households (NDHS 2006/7). In addition, another contributing factors to the obesity or overweight of the children is the mothers level of education and/or if the mother is obese or overweight herself.

In Namibia the contributing factors can be to lack of exclusive breastfeeding, poor hygiene, sanitation and caring practices as well as poor maternal health and nutrition status. Breast milk can meet the infant's energy, protein, calcium, vitamin A, Vitamin C, iron folate and zinc requirements up to $70 \%$ however, most of the Namibians are not aware of the benefits of exclusive breastfeeding (NAFIN, 2010). The infant is usually exclusively breastfed for the first two months and thereafter they are fed with bottle milk. Studies have shown that babies that are not breastfed have shown to be five times more likely to die of infectious diseases than those infants that are breastfed in the first two months of life and twice as likely to submit to infectious disease within the first half year of life.

Consequently, in some instances low sanitation coverage and sub-optimal hygiene practices such as infrequent or lack of hand washing with soap prior to feeding babies and food handling can lead to infectious diseases that can compromise the infant's nutrition. The nutrition of the child who grows up in the environment with low sanitation can be compromised due to competing with invading pathogens, (NAFIN, 2010). Although access to safe drinking water and sanitation facilities has increased considerably there are quite a number of schools with no access to safe water and sanitation systems, (MOHSS, 2008). Absence of these facilities contributes significantly to diarrhea, schistomiasis and scabies among learners which in turn can contribute to the absence rate in school.

Additionally, a third critical factor in infant and childhood malnutrition in Namibia is the mothers' nutrition and health status and care during pregnancy, (NAFIN, 2010). This was proven in the Namibia Demographic Health Survey (NDHS) 2006/7 report shows that children born to underweight mothers were two to three times more likely to be severely stunted compared to children born to normal or overweight mothers. Hence, with 1 in 10 urban and 1 in 5 rural women who are underweight respectively, the potential for the ongoing cycle of intergeneration stunting to continue is very high.

Consequently, micronutrients deficiency (which is the deficiencies of vitamin A, lodine and iron) also known as hidden hunger prevails among the under five years old. The current data available shows that Vitamin A is the most common deficiency in Namibia with $23.5 \%$ preschool children with plasma level of Vitamin A less than $0.70 \mu \mathrm{mol} / \mathrm{I}$, (NAFIN, 2010). Consequently, available data shows that 1437 children less than five years of age had anaemia while 2419 children older than five years were anaemic. The study done by Chotard, et al., 2006 cited in (NAFIN, 2010) shows that among primary school learners in Caprivi region $43,9 \%$ of boys and $33 \%$ of girls had anaemia respectively. Iodine deficiency is another public health problem in Namibia with the national prevalence rate which was found to be $28.7 \%$ with the highest being $70 \%$ was found in Kavango region, of the population with urinary iodine of less than $100 \mu \mathrm{g} / \mathrm{L}$ (WHO 2004 cited in (NAFIN, 2010).

The study done by the MOHSS 2004 on the health of the learner done in all the health directorates shows that $39.3 \%$ of students always eat and/or drink something in the morning before they go to school, while $18.8 \%$ never eat and/or drink something and $23 \%$ eating and/or drink only sometimes. Whereas male students are less likely (38.4\%) than female students (40.1\%) to eat and/or drink something in the morning before they go to school. The highest percentage of students (26.8\%) who never eat/drink something in the morning before they go to school fall in the 12 years of age group category compared to the lowest percentage of $17.5 \%$ under the category 13 to 15 years.

The main reasons why the students do not eat and/or drink in the morning before they leave for school are amongst others, not having time for breakfast (23.4\%), inability to eat in the morning (16.7\%), lack of food at 
home (13.3\%) and dislike of food at home (3.4\%). Students who reported that they do not eat and/or drink something in the morning are mostly in the age group of 12 years and younger because they didn't like the food at home while children 16 years and older (19.7\%) reported that there is always no food at home. Although the majority of learners reported having eaten and /or drink something in the morning, there is a significant number of responded who indicated of not eating anything due to lack of food at home or having enough time to prepare the food and this should not be overestimated as it can impact on the academic performance of the students, (MOHSS , 2004).

The nutritional status of Namibians particularly the one of the children is affected by the lack of access to diverse diets rich in micronutrients and less consumption of fruits and vegetables by both the adults and children. People tend to eat the same kind of food year round hence the staple food in Namibia are based on the maize meal or millet which is prepared as porridge and served with either fish, red meat or spinach, (MOHSS , 2012).

There is limited literature that shows the current nutritional status of the school going learners in Namibia and the impact thereof. However, with the current nutritional status of the mothers and the under-five year's population and the dietary behaviors of learners it shows that the primary school learners nutritional status could be compromised. This could result in reduction of resistance to diseases, impairment bone and muscle development and weakens eyesight and hearing, diminish wellbeing and activity and leads to poor concentration at school, (MOHSS, 2008; MOHSS , 2004). There is a great scarcity of local literature on school aged children, attention span in class, nutritional status of scholars and diet as well as the scholastic performance thus led to limited local literatures to be review.

\section{Purpose of the study}

The purpose of this study was to determine and describe the link between routine diet, capacity for sustained attention span and scholastic performance among Grade 2 scholars in circuit one in Khomas region.

\section{Objectives of the study}

The objectives of this study were to:

- Assess the routine diet of Grade 2 scholars in circuit one in Khomas region

- Assess Grade 2 scholars' ability for sustained attention in class in circuit one in Khomas region

- Determine the scholastic performance of Grade 2 scholars' in circuit one in Khomas region

- Describe the link between routine diet, attention span and scholastic performance among Grade 2 scholars' in circuit one in Khomas region

\section{Significance of the study}

The results of this study will contribute towards new knowledge, since no similar study was done before in Namibia. It may greatly contribute to the school feeding programs in Namibia and consequently inform the policy makers as well as the donors on where the funds should be directed. It will also provide the baseline data for the Namibia Alliance for Improved Nutrition (NAFIN), chaired by the honorable Prime Minister, and can inform relevant Ministries, Non-Governmental Organizations and development partners running school feeding programs. This study can also be replicated in other regions with a different population.

\section{METHOD}

The study undertook the quantitative and descriptive research designs which are non-experimental in nature to determine and describe the link between routine diet, attention span and scholastic performance among grade 2 scholars in circuit one in Khomas region. Quantitative research designs emphasize measurement in the collection and analysis of numerical data, causality, generalization and replication. The epistemological basis for quantitative research is the positivism paradigm. Positivism advocates the application of the methods of the natural sciences to the study of social reality (Jupp, 2006). Instrumentation is conducive to an objective, positivistic approach such as surveys, structure questionnaires, and standardized norms and standards (indexes).

In this study, data collected produced numerical values, i.e. non-numerical values from the two-week routine diet diary were converted to numbers as part of the analysis process (Jupp, 2006). Numerical data can be durations, scores, counts of incidents, ratings, or scales. Data in numerical form facilitates the measurement of variables and statistical analyses. Descriptive statistics are used to illustrate and summarize findings on key variables, and detect relationships between variables, as in correlation coefficient values. The advantage of quantitative research is that data obtained via these methods can be subject to considerable statistical analysis and can be generalized beyond the sample under investigation.

While, descriptive designs are used in the studies 
where more information is required in a particular field through the provision of a picture of the phenomenon as it occurs naturally, (Brink, 2006). Additionally, according to Brink (2006), descriptive designs are based on the following assumptions:

The variables exist in the study population as a single variable that is amenable to description.

- There is insufficient existing literature describing the study population or the variable

- The study may commence without a theoretical framework but the researcher should provide the rational for the study based on the thorough literature review.

- Existing studies may provide the rational and theoretical framework for the study at hand in the case of a known concept

- In a study where the criteria for external validity cannot be met owing to the unknown population parameters.

Descriptive design are used to gather information from a representative sample of the population, hence the correct sample should be calculated for the study. Consequently, a descriptive design uses structured observations, questionnaires, interviews and/or survey studies to arrive at the final findings and conclusion of the research.

\section{Research population}

The target population for this study consisted of all the Grade 2 scholars within circuit one in Khomas region. Scholars within the same circuit wereselected because they are taught similar academic content, and because of uniform (similar) scholastic progress assessments done within the same circuit.

Consequently, another population of interest was the parents, guardians or caregivers of the grade 2 scholars who are schooling in circuit one in Khomas region. The parents, guardian or caregivers for the grade 2 scholars were selected because they have a better understanding on what type and quantity of the food their children have eaten during the course of the two (2) weeks, additionally they also know better on what happened in their child's lives.

\section{Sampling method and sample}

Probability sampling methods were determined as the appropriate methods to be employed during the study. According to (Brink, 2006) probability sampling gives an equal opportunity for all the elements in the population to have an equal chance of being included in the sample. Consequently, it permits the researcher to estimate the sampling error, to reduce bias in the sample or sampling and it also makes it possible for the researcher to use inferential statistics correctly as well as to obtain the findings that can be generalized to the population. Hence, the study employed stratified as well as the simple random sampling, (Jupp, 2006)

Eighteen primary schools listed in circuit one were stratified into two (2) groups based on the grade 5 scholars performance as per the 2011 National Standardized Achievement Test (NSAT) whereby each subgroup had nine schools one subgroup with highly performing schools and another subgroup with low performing schools respectively. Thereafter simple random sampling was employed to select one primary school from each subgroup and to select one class from each selected schools. The parents, guardians and/or caregivers were selected based on the school and the grades selected for the study.

\section{Research instruments}

During the study five types of instruments were used for data collection, namely the structured food frequency questionnaire, a standardized Conner Teacher Rating Scale (CTRS-R), psychometric tests, performance checklist as well as the Anthropometric checklist/calculator. In order to assess scholars routine diet structured food frequency questionnaire was administered which contained instructions on how to complete the questionnaire, demographic details of the scholars as well as the responses options under different type of food groups, for a example each type of food was categorized according to certain group of food whereby for example all types of vegetables were under one category and all types of beverages were under one category to mention a few. Additionally, every type of food mentioned in the questionnaire had the colorful picture next to it in order to make it easier for the respondent. The parents were required to tick next to the most suitable portion size of food.

Consequently, next to each type of food the measurements were shown in order to make it easier for the researcher to calculate the amount of food each selected scholar ate in that particular day. Although the questionnaire seems to be comprehensive with all type of foods in Namibia, the researcher acknowledges that there might be type of food that are not listed in the questionnaire, thus provision was made under each category by leaving an open space to capture the response option others under each type of food.

The questionnaire also provides for reporting of the parents' pay-day(s) (date of payment), together with reporting of all unusual events experienced during the 
sample two-weeks that might have influenced the routine food-intake of the scholars, e.g., a birthday party, illness of the child, house guests, changed circumstances that might impact on the scholars' appetite, availability of pocket money for tuck shop purchases, reporting of specific purchases at the tuck shop, the contents of the scholars' lunch boxes (if applicable), etcetera.

Reporting of the pay-day and any unusual or additional events enables the researcher to detect unusual fluctuations in the sample routine food intake on an individual basis, e.g. any upward spiking or any downward tightening of routine food intake reported for a period of two weeks. In the event thereof that unusual fluctuations in the reported routine food intake of scholars can be attributed to specific factors, e.g., pay-day, illness, birthdays. Consequently, a response option, requiring reporting of the Grade 2-scholar's physical activity level on a daily basis was captured. The questionnaire was administered by the parents, guardian and/or caregivers of the scholars selected for the study.

In addition,in order to assess the nutritional status of scholars their height and weight were measured by trained fieldworkers. All scholars were weighed (in $\mathrm{kg}$ to the nearest $0.01 \mathrm{~kg}$ ) without shoes and jerseys using a digital scale. Height was measured (in $\mathrm{cm}$ to the nearest $0.1 \mathrm{~cm}$ ) using a stadiometer, which was placed on an even surface. All scholars stood on its base without shoes, with heels together, looking straight ahead. Thereafter the data was entered into the anthropometric checklist and/or calculator which was utilized to capture the date of birth, the date of data collection, the gender and the weight and height of the scholars. The BMI as well as the BMI percentile was automatically calculated based on the information entered.

The Third instrument the standardized Conner Teacher Rating Scale (CTRS-R) was used to obtain data on the ability of the scholars to sustained attention and was administered by the class teacher of the selected class. The CTRS-R contains the instructions on how to complete it, the demographic details of the scholars as well as the responses options that are divided into three parts. Part one focuses mostly on the attention span of the learner while part two focuses on the behavior of the scholars as well as the cognitive abilities, while part three focus was mostly on the background, the experience of the scholars or activities in the scholar's life that can lead to the way he or she behaves. Question one to ninety nine in part one to two had the scale of responses from not at all to just a little, quite a bit as well as very much while part three responses for question 91 to 100 were as follows: no, yes and uncertain.

In order to assess the scholars academic performances the academic performance checklist was used to capture the continuous assessment marks
(CASS) as well as the final first term marks for all subjects taught at that particular school. Additionally, five types of psychometric checklists namely, auditory longterm memory, auditory short-term memory, auditory sequencing, one minute reading test, visual discrimination test were administered to test performances, concentration as well as listening comprehension.

\section{Pilot study}

According to Brink, (2006) a pilot study can be referred to as the preliminary study which is a small-scale study conducted prior to the main study on a limited number of subjects from the population at hand. The main purpose of the pilot study is to investigate the feasibility of the proposed study and to detect possible flaws in the data collection instruments, such as ambiguous instructions or wording, inadequate time limits as well as to check whether the variables defined by operational definitions are actually observable and measurable. In this regards, the instruments used for the data collection during the study were piloted before the main study commenced. The structured food frequency questionnaire was piloted with five (5) parents of Grade 2 scholars from Constantia Private school, (Brink, 2009), prior to commencement of the main study to assess if all the foods eaten in Namibia were captured in the instrument.

In order to ensure food frequency questionnaire content and face validity, copies were presented to a Nutrition Technical Advisor for Centre for Disease Control (CDC) in Namibia, Nutritionist at Ministry of Health and Social Services as well as the Medical Officer at Tuberculosis (TB) subdivision within the Ministry of Health and Social Services. The reviewers looked at the ambiguity, language, wording, confusing statements, coherent and completeness of the instruments. Additionally, the content validity of the questionnaire and the checklistswas established through extensive literature review. All the recommendations made were incorporated accordingly. However, the Conners Teacher rating scale, the psychometric checklist as well as the anthropometric checklist and/or calculator were not piloted because they are standardized international instruments. However, despite the Conners Teacher rating scale being a standardized instrument it was revised to accommodate the Namibian situation.

\section{Procedure for data collection}

The tools used for collecting data were Focus Food Frequency questionnaie; Conor Teacher Rating Scale; 
Anthropometric checklist and Psychometric tests and Performance checklist describe as follow:

\section{A. Focus Food Frequency questionnaire}

The Focus Food Frequency questionnaire was the only tool piloted before the initial data collection. It was piloted with five (5) parents from Constantia Primary school. After necessary amendments were made the two research assistants were trained on all the data collection tools. While the two class teachers for the two primary schools were only trained on the Connor Teacher Rating Scale. The parents were trained on how to complete the Focus Food Frequency questionnaire for the period of two weeks. To limit variables emanating from 'pay-day' effects, i.e., availability of finances that might increase/decrease availability and intake of certain foods, the questionnaire was administered during the middle of the month, i.e., recording of routine food intake commences at the 2ndweek of the month, and concluded at the end of the 3rd week of the month.

\section{B. Anthropometric checklist}

Thereafter, the data was entered and analyzed in order to categorize the scholars based on their nutritional status (for example underweight, normal, overweight and obese). Two scholars whose parents completed the FFF questionnaire for two weeks were selected from each category. Using the questionnaire with the two (2) weeks focused food frequency; methods derived from the dietary approach were employed to determine baseline nutritional needs, limitations, and food intake patterns as it transpires from standardized nutritional indexes.

\section{The Connor Teacher Rating Scale}

During the first week the teachers from both schools completed the Connor Teacher Rating scale on all the scholars whose parents consented for them to participate in the research. During the second week the scholars' height and weight were measured at both schools.

\section{Psychometric tests}

During the last week of completing the Focus Food Frequency questionnaire five psychometric tests were done for 15 minutes with each scholar within school settings

1. Psychometric test 1: Auditory Long term memory
The auditory long term memory psychometric test was read slowly to the scholar with good pronunciation. Thereafter the scholar must have repeated the story to the test administrator in no particular order.

2. Psychometric test 2: Auditory Sequencing Before the auditory sequencing the administrator did the practice example with scholars one at the time. Thereafter, the administrators read level one which comprised of first row consisting of number, second row consisting of letters and third row consisting of mixers of number and letters to the scholar at the slow pace. The scholar was to repeat each row in sequential order to the administrator and was to successfully complete each row before moving to the next level.

3. Psychometric test 3: Auditory Short term memory Before the auditory short term memory the administrator did the practice example with scholars one at the time. All levels in auditory short term memory consisted of letters. The administrators read level one which comprised of first row, second row and third row to the scholar on the slow pace. The scholar was to repeat each row in sequential order to the administrator and was to successfully complete each row before moving to the next level.

4. Psychometric test 4: One Minute Reading Test

The scholar was requested to read as quickly and correctly the words horizontally as if reading from a book for a limited time of one minute but they were not informed of the time limit. At the end of one minute the administrator indicated where the scholar ended but the scholar where allowed to continue reading so they cannot be suspicious.

5. Psychometric test 5: Visual Discrimination Test There was no time limit for visual discrimination test but the scholar was to work as quickly as he or she can by comparing the word in the first column on the left side with those in the rest of the row and indicate by crossing out the words that differs from the stimulus word in the first column on the left side. No indication of wrong answers or fright was indicated during test-taking since this indication could have negative or positive reinforcement influencing the test results in one or another way.

\section{E. Academic Performance checklist}

This checklist captured the performances of each selected scholars from both schools. Each subject CASS marks as well as the examination for the first term was captured. Thus, scholastic performance reports of Grade 2-scholars were analyzed per subcategory. Thereafter, all data were entered into Epi-info and Microsoft excel respectively and later were exported to Statistical 
Package for Social Sciences (SPSS) 20.0 for analysis as articulated in section 3.9 below.

\section{Data analysis}

The researcher scrutinized the type of food eaten by scholars and determined the number of calories intake for the week and thereafter divide by seven to get the number of calories intake per day per scholar. Anthropometric data was entered into the BMI group metric calculator which is the Microsoft Excel version. The BMI group metric calculator automatically calculates the BMI as well as the BMI percentile which is more appropriate to use for the children.

Connor Teacher Rating Scale data was entered into Epi-info while the academic performance data was entered into the Microsoft Excel form. However, in order to analyze psychometric tests the researcher used standardized norms to look for common patterns. Thereafter, all the data were exported to SPSS 20.0 program to be analyzed accordingly. Descriptive statistics, i.e. one-variable (univariate) and multivariate techniques were used, e.g. the one-way and two-way ANOVA F-test. Multivariate analysis looks at the relationship between several variables simultaneously, often to construct causal models. By contrast, univariate analysis seeks to describe individuals or social groups using one variable at a time. This was done by frequency distribution counts of responses to the questionnaire and Connors Attention Scale.

The frequency in each category was converted to a percentage which provides a standardized basis for comparison between categories and also between subcategories. Frequency distributions are portrayed visually as bar charts or pie charts. Other descriptive statistics include measures of central tendency or average (means, medians and modes) and measures of dispersion (standard deviation and variance). The latter indicate how closely scores are bunched around an average and, therefore, tell the researcher about the overall shape of a frequency distribution for any given variable.

Descriptive statistics do not by itself provide an analysis in terms of relationships between two or more variables, as in a causal model or any form of multivariate analysis. In this study, univariate analysis is the first preliminary stage, followed by advanced multivariate analyses, referring to the set of statistical methods employed in the interpretation of data when more than one variable property is measured for each case in the sample, e.g. the Chi-Square Test for Independence.

The methods explore covariation among variables how the variables vary together either in order to establish relationships among variables or to allocate cases to categories. The researcher employed a numerical taxonomy procedures for data analysis, i.e. a set of methods using univariate information to allocate cases to pre-existing categories or to construct a system of categories from scratch and allocate cases to those categories, i.e. the use of quantitative information in sorting things 'into kinds', allowing for investigation of relationships that cannot be investigated through linear modeling (Jupp, 2006).

\section{Ethical considerations}

Permission to conduct the studywas obtained from the relevant authorities prior to the pilot study as well as the actual data collection within Khomas region. The first letter requesting permission to conduct the survey within schools was addressed to Ministry of Education Khomas Regional Office whereby it was discussed at the research committee. Once the permission was granted a second and detailed letter was written and addressed to the respective school principals in circuit one. Thereafter, a third detailed letter and/or consent letter was addressed to the parents of the scholars selected for the study to inform them about the study accordingly and for them to voluntarily consent for their children to participate in the study.

The consent was written on the cover page of each questionnaire. The consent included the purpose of the study, objectives of the study, methods used, the duration of the study and lastly the identity and qualification of the researcher and or the assistant researcher. The participants were made aware that they had the right to withdraw at any time if by anyway they felt uncomfortable.

Confidentiality and anonymity, Although the instruments made provision for the name of the participants in order to ensure anonymity the questionnaires were numbered, thus in the database only identity numbers corresponding to that particular participant were entered. The master list with the participants' names and code number was kept separate from the data collected in order to protect the participants' identity. Additionally, the participant's information was not shared with other people other than those who were working on the study.

The worth and dignity of the participants was maintained. The invasion of privacy was prevented by making sure no information was shared without the participants knowledge or against his or her wish will, because by invading an individual's privacy might cause loss of dignity, feeling of anxiety, guilty, embarrassment and shame. The instruments and methods used during 
Table 1: Nutritional status distribution for both schools

\begin{tabular}{|c|c|c|}
\hline \multicolumn{3}{|c|}{ Statistics } \\
\hline \multicolumn{3}{|l|}{ BMI percentile } \\
\hline $\mathrm{N}$ & Valid & 57 \\
\hline & Missing & 0 \\
\hline Mean & & 2.07 \\
\hline Median & & 2.00 \\
\hline Mode & & 2 \\
\hline Std. Deviation & & .651 \\
\hline Variance & & .424 \\
\hline Skewness & & 1.543 \\
\hline Std. Error of Skewness & & .316 \\
\hline
\end{tabular}

the interview were known by the participants. During data collection, the researcher did not gather the information, for example by taping conversation or using hidden cameras and microphone without their knowledge. In this situation, all data collection methods were scrutinized to protect participant's privacy.

\section{RESULTS}

\section{Participation rate among the study population}

The total number of the sample population was 75 scholars, however only 57 scholars participated in the study as indicated in Chapter 3. Out of the 57 scholars who participated in the study, 28 were MH Greef Primary school while 29 Khomasdal Primary school scholars respectively from which $\mathrm{BMI}$, attention span and academic performances were collected. The scholars were categorized into four nutritional statuses based on their BMI percentile (underweight, normal, overweight and obese) from which 2 scholars were randomly selected from each category to make up the subgroup of 8 scholars. Thereafter, the five types of psychometric tests and FFFQ were only administeredfor the 8 scholars. The 8 scholars' subgroup was selected based on the assumption that the findings can be generalized to the rest of the group.

\section{Results of analyzed data}

Out of 41 scholars from Khomasdal Primary school only $50.9 \%(n=29)$ scholars participated in the study while from MH Greef Primary school out of 34 scholars only 49.1\% ( $n=28)$ scholars participated in the study. Since the participants were below the age of consent stipulated as 21 years in (Hubbard, 1997 ), they needed their parents or guardians to consent for them to participate in the study, thus led to the number of participants to reduce as the study was voluntary as some parents or guardians refused to participate from the onset of the study.

Majority of participants were females $65 \%(n=37)$ while $35 \%(n=20)$ were males. The proportion of females participated in the study compared to males mirrored the actual proportion because majority of scholars in both classrooms were females. Consequently, the proportion of sex in the classroom is mirrored by the general population in Namibia since $49 \%$ are men comparing to 51\% female respectively, (National Planning Commission , 2012 ). In this regard, there is a greater probability for each classroom in Namibia particularly in circuit one in Khomas region to have more females than males.

\section{Routine diet of Grade 2 scholars}

\section{Nutritional status}

Table 1 above shows that the nutritional status of the scholars is normally distributed because the mean, mode and median are the same $(n=2)$ and thus represent that most of the scholars have a normal nutritional status.

Measuring of the scholars BMI percentile who participated in the study revealed that most of them $79 \%$ $(n=45)$ had a normal weight comparing to their weight and height, (Figure 1 below). While 11\% $(n=6)$ were underweight, $7 \%(n=4)$ were obese and only $3 \%(n=2)$ of the scholars were overweight. Malnutrition remains a public health problem in Namibia since almost one out of every three children under the age of five is malnourished and that most research shows that one-third of children in the developing world are either underweight or stunted (low height for age) while more than $30 \%$ of the developing world's population suffers from micronutrient deficiencies, (MOHSS, 2012; NAFIN, 2010).

The findings from this study has mirrored the outcome from (NAFIN, 2010) study that shows the geographical 


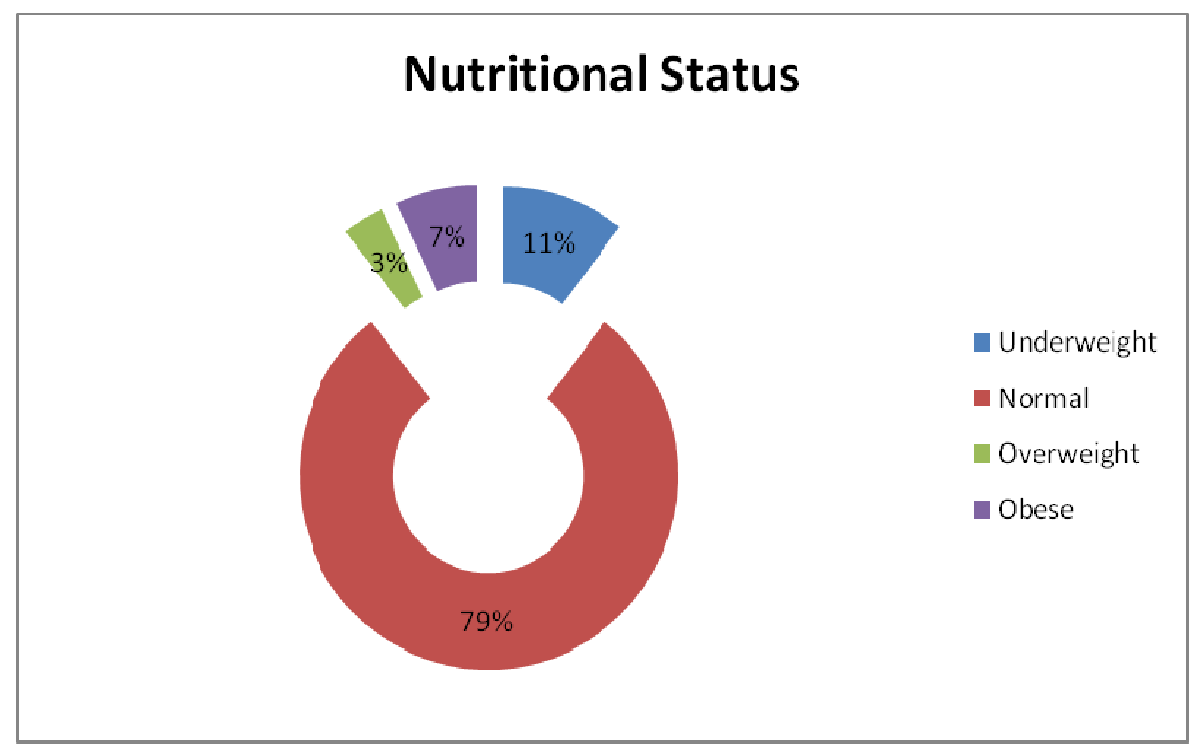

Figure 1: Nutritional status of the scholars

general pattern in Namibia which indicates that the regions with high levels of poverty, low literacy rates, high HIVIAIDS prevalence rate and with predominantly rural populations have the highest levels of stunting ranging from $39 \%$ in Kavango, Hardap, Ohangwena to $22 \%$ in Khomas, Erongo and Omaheke to mention the few. This study shows that more scholars nutritional status is normal. This finding is not surprising considering the region and the geographic area of the selected schools. It also shows that nutritional status is not normally distributed across populations, regions, districts, constituencies, schools and circuits. In some circuits or schools it could be higher whereas in others it could be less as it is in this case. Previous study done by Ying, Fengying, Wenjun, Keyou, Daxun, and Onis, (2003) shows that there was a significant difference of underweight across different provinces in China, the Guizhou had the highest prevalence of underweight, followed by Hunan and Guangdong, with prevalence above $30 \%$. While, the lowest prevalence underweight (12.7\%) was in Hubei province.

\section{Focused Food Frequency Questionnaire (FFFQ)}

As mentioned earlier, the FFFQ was only administered to 8 scholars; two scholars were randomly selected from each nutritional status (undernourished, normal, overweight and obese) to make up 8 scholars. Out of the 8 scholars who participated in this study $75 \%(n=6)$ of the respondents were female while $25 \% \quad(n=2)$ of the respondents were male. These results confirmed the results yield in figure 1, in general there are more females than male therefore for any randomly selected sample there will be more females than males.

Table 2 below shows that most scholars were from Khomasdal Primary school $75 \%(n=6)$ while only $25 \%$ $(n=2)$ of scholars were from MH Greef Primary School. The results below mirrored the results $(\mathrm{N}=57)$ yield on page 57 , figure 1 , which shows that most scholars came from Khomasdal Primary school comparing to $\mathrm{MH}$ Greef Primary school thus it make sense to have more scholars for $(\mathrm{N}=8)$ cohort to be from Khomasdal Primary School.

Table 3 below shows that of the 2 scholars whose nutritional status was normal, one indicated that he normally eats breakfast while another one indicated that he normally does not eat breakfast. One of the two obese scholars indicated having breakfast regularly while the other one indicated not having breakfast regularly. Both overweight scholars have breakfast on regular basis while the other two scholars who were underweight indicated not having breakfast on the regular base. Table 3 below shows that there is a significant positive relationship between breakfast and scholars nutritional status; not having breakfast can be one of the contributing factor to current nutritional status, for example both underweight scholars did not regularly take breakfast, meaning that there is no glucose to keep them going throughout the first lessons before the first break.

Table 4 below shows that out of the 6 female scholars 4 indicated that they do not usually have breakfast regularly, while only $2(33 \%)$ indicated that they usually have breakfast. All male scholars $n=2(100 \%)$ indicated that they usually have breakfast on regular basis. Thus, 
Table 2: Schools were the scholars who participated in the study were currently studying

\begin{tabular}{lcc}
\hline NAME OF THE SCHOOLS & FREQUENCY & PERCENTAGE \\
\hline Khomasdal Primary School & 6 & 75 \\
MH Greef Primary School & 2 & 25 \\
Total & $\mathbf{8}$ & $\mathbf{1 0 0}$ \\
\hline
\end{tabular}

Table 3: Relationship between the nutritional status of the scholars and breakfast intake

\begin{tabular}{|c|c|c|c|c|}
\hline \multirow{2}{*}{\multicolumn{2}{|c|}{ Nutritional status }} & \multicolumn{2}{|c|}{ Breakfast } & \multirow{3}{*}{$\begin{array}{c}\text { Tota } \\
2 \\
\end{array}$} \\
\hline & & \multirow{2}{*}{$\begin{array}{c}\text { No } \\
1\end{array}$} & \multirow{2}{*}{$\begin{array}{c}\text { Yes } \\
1 \\
\end{array}$} & \\
\hline \multirow{4}{*}{ BMI percentile } & Normal & & & \\
\hline & Obese & 1 & 1 & 2 \\
\hline & Overweight & 0 & 2 & 2 \\
\hline & Underweight & 2 & 0 & 2 \\
\hline \multicolumn{2}{|l|}{ Total } & 4 & 4 & 8 \\
\hline
\end{tabular}

Table 4 shows the relationship between gender and breakfast

\begin{tabular}{|l|c|c|c|}
\hline \multirow{2}{*}{ GENDER } & \multicolumn{2}{|c|}{ BREAKFAST } & \multirow{2}{*}{ Total } \\
\cline { 2 - 3 } & No & Yes & 6 \\
\hline FEMALE & 4 & 2 & 2 \\
\hline MALE & 0 & 2 & 8 \\
\hline TOTAL & 4 & 4 & \\
\hline
\end{tabular}

the results from this study differed from the study done by MOHSS 2004 which showed that males were less likely (38.4\%) than female students (40.1\%) to eat and/or drink something in the morning before they go to school.

Figure 2 below shows that on average scholars who eat breakfast on regular basis had higher calories intake 8127 during week 1, 6963 during week 2 than two scholars who did not eat breakfast on regular basis, 5035 during week 1, 4874 during week 2 respectively. The calories of scholars who skipped breakfast was lower when compared to those scholars who had breakfast. The former had more than 12 hour gap between dinner and breakfast.

Figure 3 below shows that on average obese and overweight scholars had higher calories intake for both weeks compared to normal and underweight scholars. It is advisable that children eat food that gives them high calories as they are still in a developmental stage, but then it becomes unhealthy for children to become overweight or obese as this implies that either there is less physical activity or that these scholars became obese and overweight due to genetic factors and/or sedentary lifestyles such as sitting in front of the television after school.
Table 5 below shows that the two scholars whose nutritional status was overweight both ate breakfast on regular basis and their performance in both arithmetic and reading was average and they both did not have attention impairment. While the scholars whose nutritional status was normal both did not have attention impairment and the academic performance in both reading and arithmetic was average while one usually have breakfast on the regular base and the other one does not have breakfast on the regular base.

One obese scholars usually have breakfast on the regular basis showed average in academic performance, with regard to reading skills and above average in arithmetic and had no impairment of attention. While scholar 6 who does not eat breakfast on the regular basis performed below average academically but had significant attention impairment. Whilst, scholar 7 and 8 who are both underweight and both did not eat breakfast on the regular basis, however one of them performed on average academically and had no attention impairment; while the other performed below average academically and had significant attention impairment.

According to AL-Oboudi, (2010), if the child has more than the 12 hour gap between dinner and breakfast can 


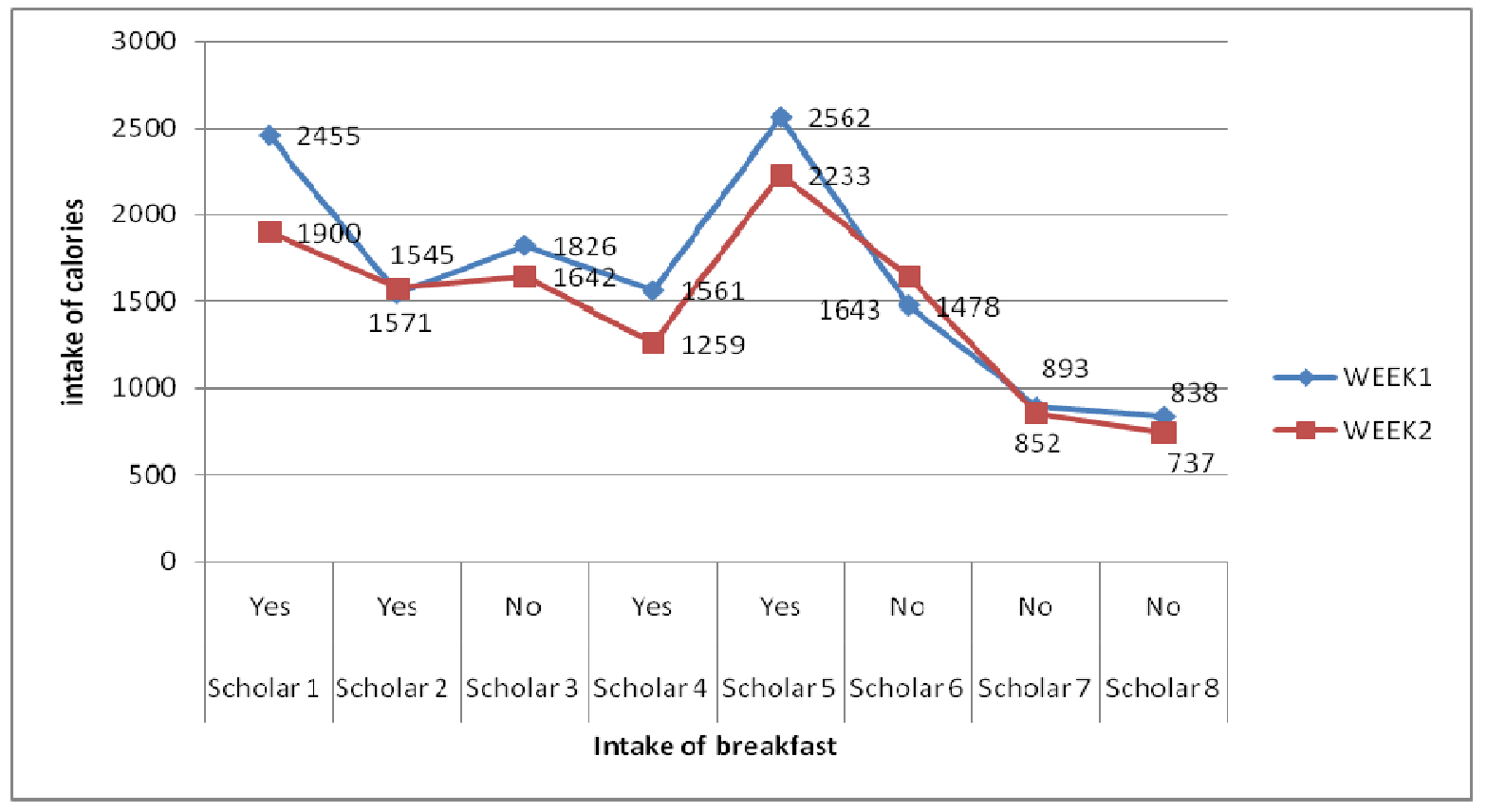

Figure 2: Relationship between the intake of breakfast and overall calories intake in the two weeks

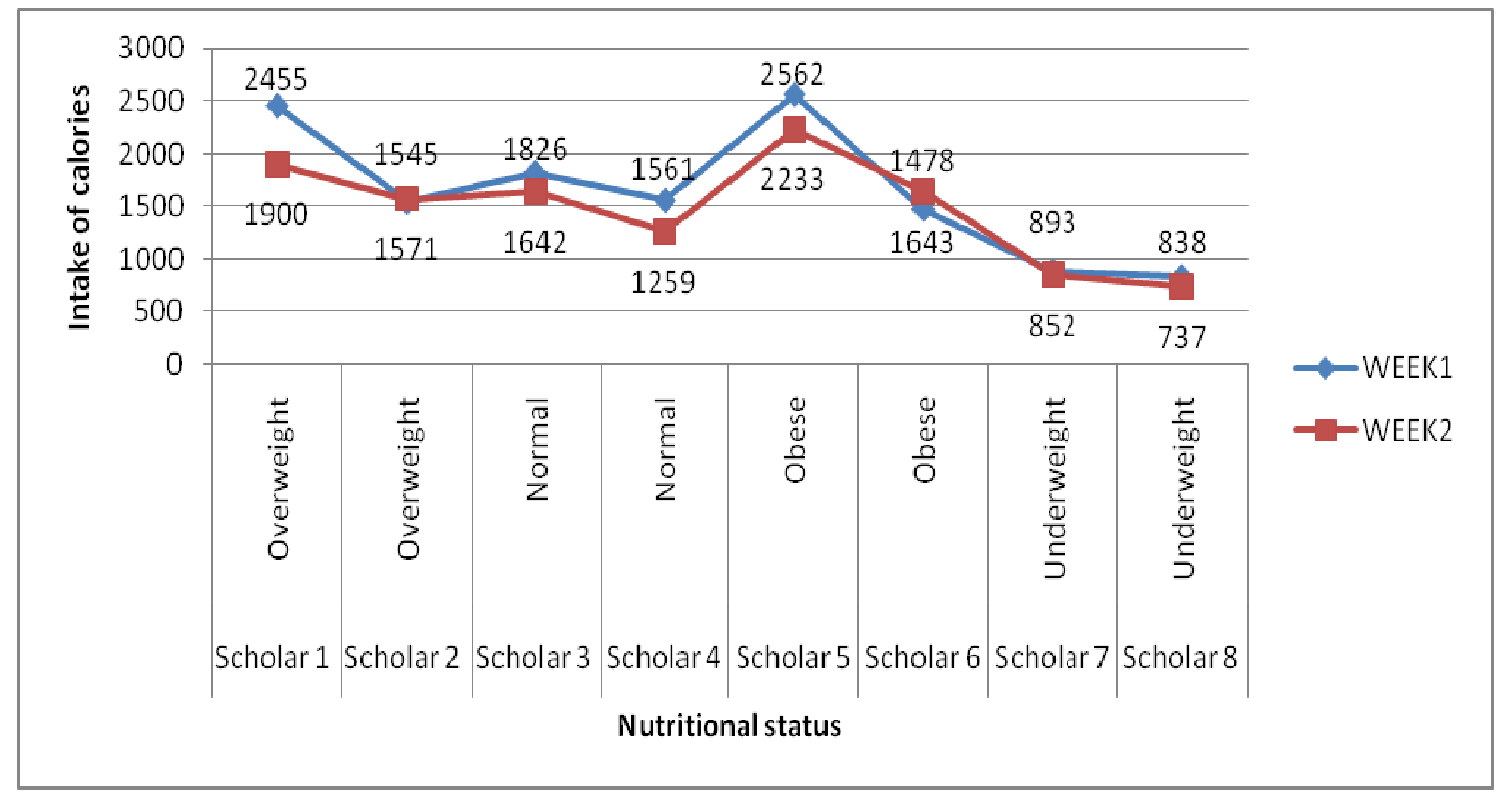

Figure 3: Relationship between the nutritional statuses of scholars and the overall calories intake during the two weeks

cause a decline in blood glucose levels and lead to glucose deprivation which in turn can result in a rapid disturbance in cerebral function if it happens in sufficient degrees. Additionally, usually missing breakfast can have negative effects on cognitive performance, attention span as well as academic performance, (Anding 2010; AL-
Oboudi, 2010). This study has confirmed the studies done by (AL-Oboudi, 2010; Anding 2010) respectively. Table 5 below indicates that all scholars $100 \%(n=4)$ who ate breakfast despite their nutritional status performed on average for both reading and arithmetic and had no attention span impairment. While $50 \%(n=2)$ of scholars 
Table 5: Shows the scholars academic performance, the BMI, attention span as well as eating breakfast

\begin{tabular}{lccccc}
\hline ID & BMI percentile & Breakfast & Reading & Arithmetic & Attention span \\
\hline Scholar 1 & Overweight & Yes & Average & Average & No impairment \\
Scholar 2 & Overweight & Yes & Average & Average & No impairment \\
Scholar 3 & Normal & No & Average & Average & No impairment \\
Scholar 4 & Normal & Yes & Average & Average & No impairment \\
Scholar 5 & Obese & Yes & Average & Above Average & No impairment \\
Scholar 6 & Obese & No & Below Average & Below Average & Significant Impairment \\
Scholar 7 & Underweight & No & Average & Average & No impairment \\
Scholar 8 & Underweight & No & Below Average & Below Average & Slightly Impairment \\
\hline
\end{tabular}

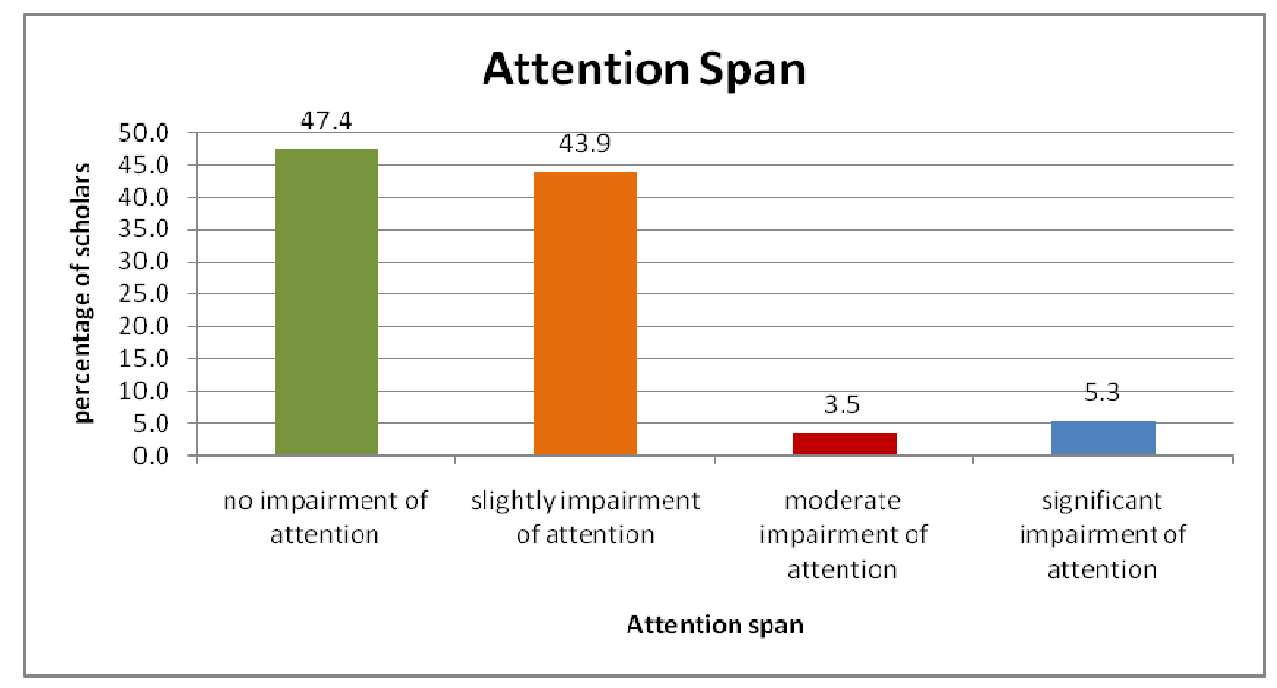

Figure 4: Attention span among the scholars who participated in the study

who indicated not having breakfast performed below average for both reading and arithmetic and had some sort of attention span impairment.

According to Florence, Asbridge, and Veugelers, (2008) undernourished children have shown decreased attendance, attention and academic performance they also experience more health problems compared to wellnourished children. This study agrees with previously described findings. Table 5 above, shows that $50 \%$ of the undernourished scholars performed below average in both reading and arithmetic and had slight attention span impairment.

\section{Ability for sustained attention in class}

The Teacher Connor scale that was completed by the class teachers of both the classes from both schools revealed that most scholars' $47.4 \%(n=27)$ showed no impairment in giving attention or concentrating in the classroom while $43.9 \% \quad(n=25)$ showed slightly impairment of attention, $5.3 \%(n=3)$ showed significant impairment of attention and only 3.5\% $(n=2)$ showed moderate impairment of attention, (Figure 4). According to Florence, Asbridge, and Veugelers, (2008) undernourished children have been shown to have decreased attendance in school and attention span thus in turn it means if the child has a normal weight their attendance in schools will be excellent and their attention span will be at acceptable rate. This study agrees with the above study, since most scholars' nutritional status was normal (Figure 4).

\section{Possible confounding factors}

In addition, to the Teacher Rating scale questions, 10 questions were added to assess other possible 


\section{Child often absent from school}

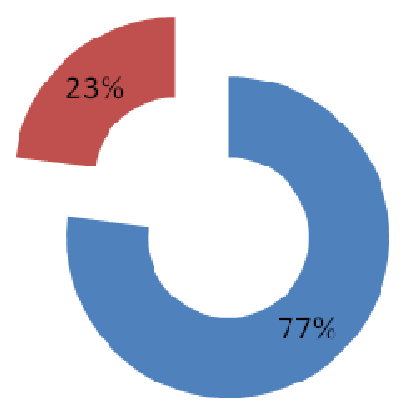

Figure 5: Percentage of scholars often absent from school

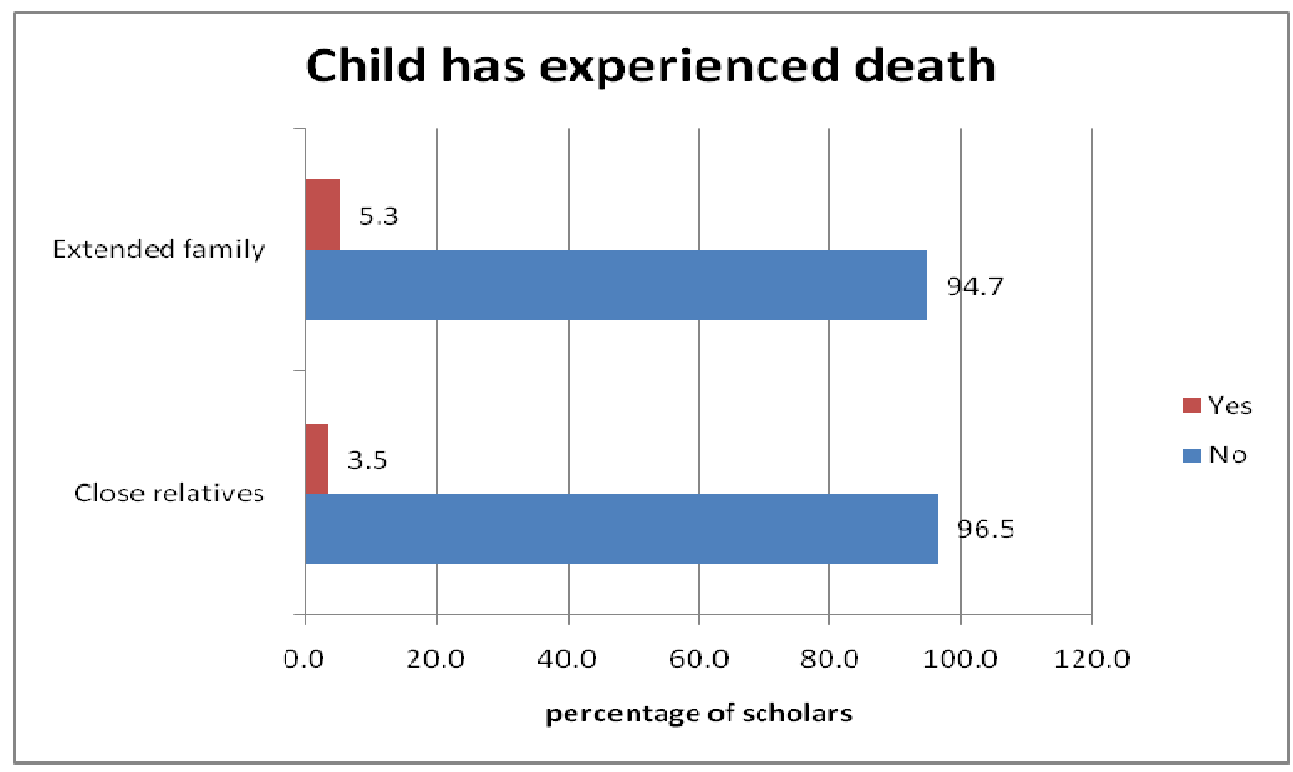

Figure 6: Scholars who experienced any death during the past month

confounding factors that may contribute to the performance of the scholars in schools. The data was analyzed using SPSS and the results of the 10 questions are presented in details below. Figure 4 below shows that most of the scholars $77 \%(n=44)$ were never absent from school without the knowledge of the class teachers, whereas $23 \%(n=12)$ scholars were always absent from school with reasons unknown by their class teacher. Most scholars whose nutritional status was normal (Figure 6 above), had no attention impairment (Figure 4) and where not absent from school unless they had a good reason known by the class teachers such as illness, (Figure 5 above), this implies that most scholars where supposed to performed above average in both arithmetic and reading (English as $2^{\text {nd }}$ language) but they are performing below the average.

Figure 6 above shows that most scholars 51\% $(n=29)$ are often absent from school due to illness, while $49 \%$ $(n=28)$ were often not absent from school due to illness. Thus, although the majority of scholars had a normal 


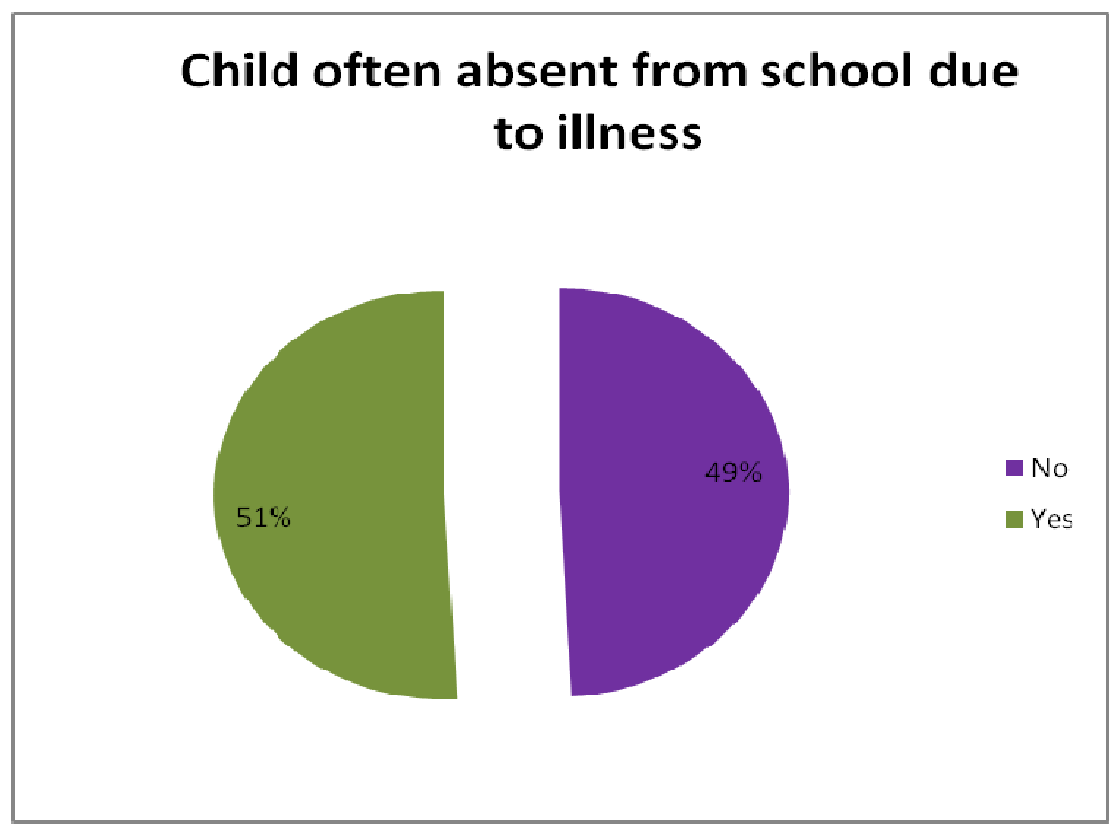

Figure 7: Percentage of scholars often absent from school due to illness

Table 6: Scholars who were directly or indirectly involved in trauma during the past month

\begin{tabular}{lcccc}
\hline & \multicolumn{2}{c}{ Indirectly involved in trauma } & \multicolumn{2}{c}{ Directly involved in trauma } \\
\hline No & Frequency (N) & Percentage (\%) & Frequency (N) & Percentage (\%) \\
Yes & 54 & 94.7 & 53 & 93 \\
Uncertain & 2 & 3.5 & 3 & 5.3 \\
\hline
\end{tabular}

nutritional status 79\% (Figure 6 above) most of them felt sick according to figure 7 above thus they missed out on some lessons in both arithmetic and reading (English as $2^{\text {nd }}$ language).

Consequently, missing some classes can lead to scholars to not complete some homework's which in turn can contribute to the low CASS marks as well as low term marks. In this regard, this can be one of the contributing factors to the poor academic performance of the scholars in both subjects.

Figure 7 above shows that most scholars did not experience any kind of death be it their close relatives such as father, mother or siblings or be it the extended family such as uncle, cousin, aunt or grandparent, $94.7 \%$ $(n=54)$ and $96.5 \%(n=55)$ respectively. However, there were few scholars who experienced the death of both their close relatives $3.5 \%(n=2)$ and that of extended family members $5.3 \%(n=3)$.
This implies that losing a close or extended family does not have a significant impact on the academic performance of the scholars since is only a small portion of scholars lost their parents comparing to those who did not lose any parent or extend family.

Table 6 above shows that most of scholars 93\% $(n=53)$ and $94.7 \%(n=54)$ did not experience any form of trauma be it directly (such as child him or herself getting involved in a car accident, parents divorcing, family violence or abuse) or indirectly (such as the child family getting involved in a car accident or abuse). On the other hand few scholars 5.3\% $(n=3)$ and $3.5 \%(n=2)$ were directly and indirectly involved in trauma for example some of their parents were in the process of divorcing or separating, whereas some of them had to relocate from other places to Windhoek. For 1.8\% $(n=1)$ the teacher(s) were uncertain if the scholar was traumatized directly or indirectly event. 
Table 7: Scholars whose primary caregiver has left the family

\begin{tabular}{lcc}
\hline Child's primary caregiver has left family & Frequency $(\mathrm{N})$ & Percentage(\%) \\
\hline No & 51 & 90 \\
Yes & 6 & 11 \\
\hline
\end{tabular}

Table 8: Financial status of the child has changed significantly in the last month

\begin{tabular}{lcc}
\hline Financial status of the child's family & Frequency (N) & Percentage (\%) \\
\hline No & 53 & 93 \\
Yes & 4 & 7 \\
\hline
\end{tabular}

Table 9: The frequency of movement amongst the study population

\begin{tabular}{lcc}
\hline Child has been nomadic & Frequency $(\mathrm{N})$ & Percentage (\%) \\
\hline No & 54 & 94.7 \\
Yes & 3 & 5.3 \\
\hline
\end{tabular}

Table 10: Adult versus child headed household

\begin{tabular}{lcc}
\hline Child lives in the child-headed house & Frequency $(\mathbf{N})$ & Percentage $(\%)$ \\
\hline No & 49 & 86 \\
Yes & 6 & 10.5 \\
Uncertain & 2 & 3.5 \\
\hline
\end{tabular}

Since most scholars were not traumatized, thus basically means that trauma cannot be one of the contributing factors on how scholars' academically performed poorly. Thus, more studies need to be employed to investigate why scholars academically performed poorly despite not being traumatized.

Table 7 above shows that most scholars' 90\% $(n=51)$ primary caregiver did not leave the family during the past month while for $11 \%(n=6)$ primary caregivers had left the family in the last month due to other reasoning such as parents getting divorced and separated excluding death. These results demonstrate that trauma cannot be a contributing factor to scholar's poor academic performance as the majority of scholars as shown in table 7 above did not leave the family, meaning that they were leaving at home which they are used to.

Table 8 above shows that most scholars 93\% $(n=53)$ financial status did not change significantly in the last one month while $7 \%(n=4)$ scholars' financial status had changed significantly in the last one month due to one parent moving out of the house or the child moving from one parent to another such as aunt, orphanage home, uncle and grandparents. Since, most scholars' financial status was not changed; this cannot be a contributing factor to poor academic performance of scholars in both schools.

Table 9 above shows that most scholars $94.7 \%(n=54)$ have not been nomadic, they did not move from one caregiver to another, while $5.3 \% \quad(n=3)$ have been nomadic, they moved from one caregiver to another.

Among those scholars who moved, some moved from their biological parents to their grandparents, while others moved to their aunts, uncle or as to the orphanage homes. Since most of scholars did not move from one parent to another as indicated in table 9 thus this did not contribute to poor academic performance of scholars.

Table 10 above shows that most scholars 86\% $(n=49)$ are not living in the child-headed household while $10.5 \%$ $(n=6)$ are living in the child-headed household but is only for $3.5 \% \quad(n=2)$ scholars whom the teachers were uncertain whom they were living with. Since most scholars were living in parents headed households, this factor has insignificant impact on scholars' academic performance. 
Table 11: Arithmetic skills distribution in both schools

\begin{tabular}{|c|c|c|}
\hline Statistics & & \\
\hline $\mathrm{N}$ & Valid & 57 \\
\hline & Missing & 0 \\
\hline Mean & & 3.58 \\
\hline Median & & 4.00 \\
\hline Mode & & 4 \\
\hline Std. Deviation & & .533 \\
\hline Variance & & .284 \\
\hline Skewness & & -.694 \\
\hline Std. Error of Skewness & & .316 \\
\hline
\end{tabular}

\section{Scholastic performances of Grade 2 scholars'}

\section{Academic Performance}

Table 11 above shows that performance in arithmetic skills is normally distributed because the mean, mode and median is the same $(n=4)$ and thus represent that most of the students performed below average in arithmetic.

Most of the scholars 59.6\% $(n=34)$ who participated in the study performed below average in arithmetic (mathematics) while 38.6\% $(n=22)$ performed on average and only $1.8 \%(n=1)$ performed above average (Figure 8 below). Performing below average implies the highest scored in arithmetic was $44 \%$, while the scholars who scored on average scored between $45-64 \%$ and above average scholars scored between $65-79 \%$ and no scholars scored $80-100 \%$. The results imply that the scholar's ability to perform in arithmetic (which is basically more about adding and subtracting) is critically below average and if the foundation is poor this will affect their academic performance as they progress to other classes. The study done by (Halterman et al., 2001) showed that the children with iron deficiency were twice as likely to score below average on mathematics tests even after allowing for potential confounders and this findings were more pronounced among girls. This could be the case with Namibian scholars, although this study did not test for the level of iron deficeincy.

Most scholars $61.4 \%(n=35)$ who participated in the study performed below average in reading (English $2^{\text {nd }}$ language) while for $38.6 \%(n=22)$ their performance was average, (Figure 9 below). The results show that the scholars are not performing well in reading skills as no scholars performed above average. Performing below average implies that the highest scored in reading was $44 \%$, while the scholars who scored on average scored between 45-64\%; no single scholars performed above average (65-79\%) and $80-100 \%$. The results imply that the scholar's ability to read English as $2^{\text {nd }}$ language is critically below average.

\section{Psychometric Tests}

The results shown in tables below are for the five psychometric tests namely Auditory sequencing, Auditory short-term memory, Auditory long-term memory, word recognition (reading) as well as visual discrimination done with the 8 sub-group cohorts who participated in FFFQ to assess their level of scholastic functioning.

\section{Level of scholastic functioning}

\section{Auditory sequencing}

The researcher was required to read a row comprised of letters and numbers at the time to the scholar see annexure $\mathrm{K}$. Whereas, the learner was required to remember what was read to him/her and to repeat to the researcher in the same order as was said to him/her in order to move to another level. However, if the learner unsuccessfully completes a level after three attempts, the test was automatically stopped. The study showed statistically significant deviation (developmental backlog) for cohort of participants in terms of Auditory Sequencing, since 5 scholars ( 2 underweight, 2 obese and 1 normal) out of a cohort of 8 participants demonstrated a developmental backlog in terms of Auditory Sequencing $(p=0.04431)$. All sub-group of participants with obese and underweight BMI demonstrated statistically significant performance below par, while only 1 of the normal participants demonstrated statistically significant below par skills. Both of the overweight participants performed on par. A study done by Florence, Asbridge, and Veugelers, (2008) showed that undernourished children had decreased attendance, attention and academic 


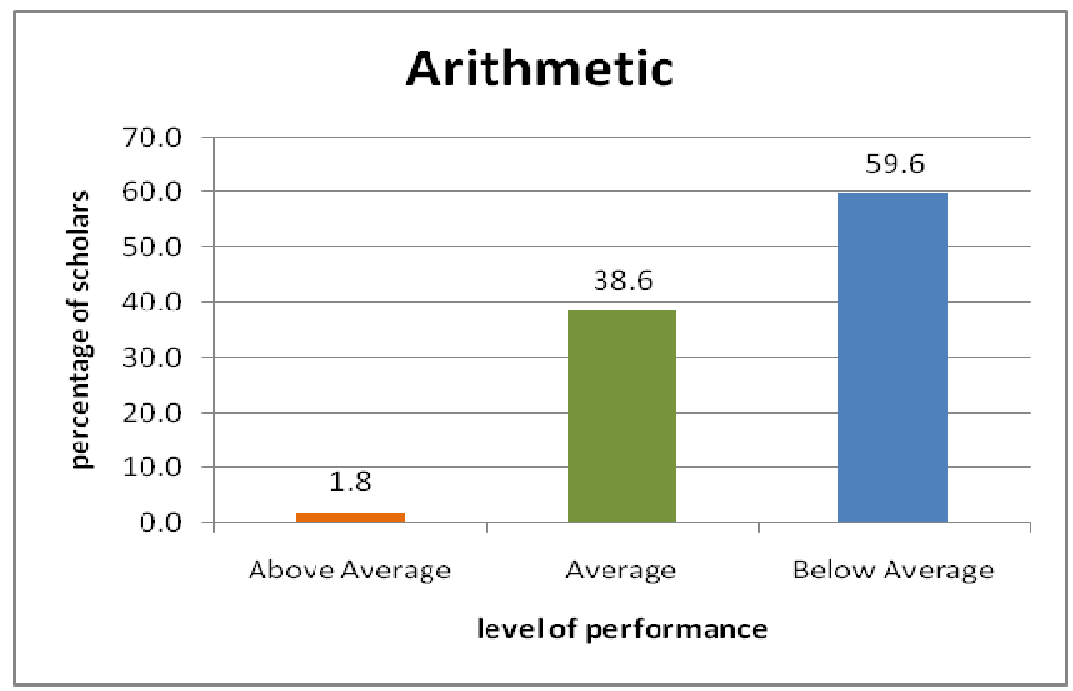

Figure 8: Overall performance of scholars in arithmetic

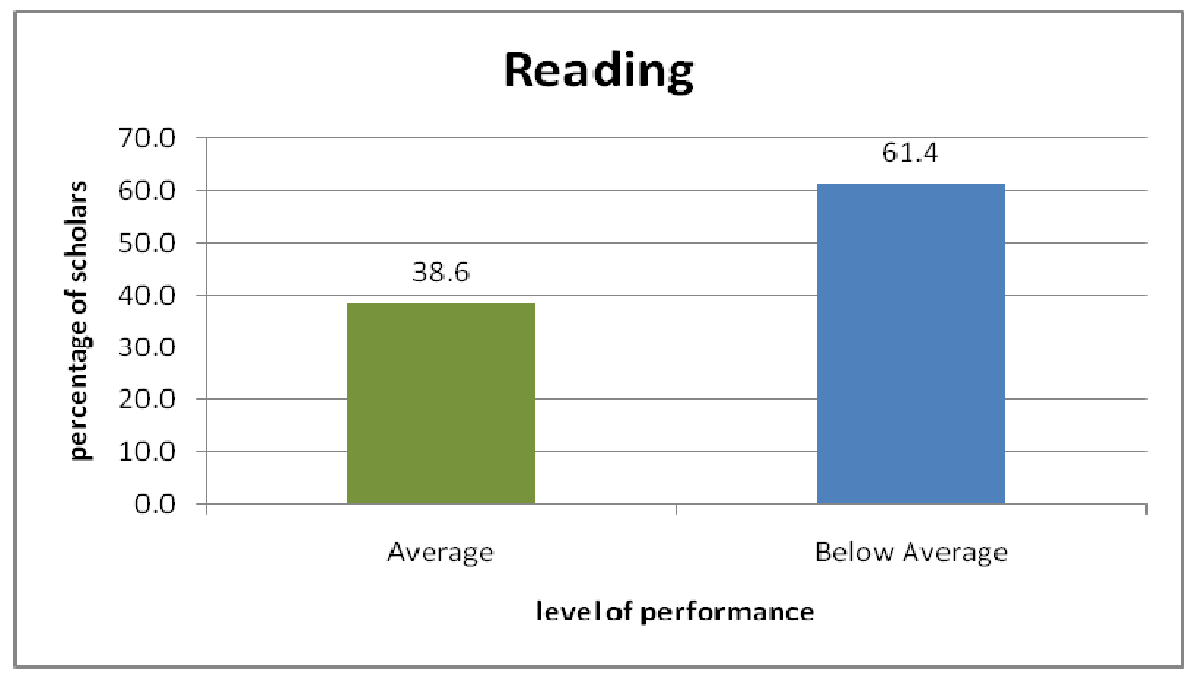

Figure 9: Overall performance of scholars in reading (English 2nd language)

performance they also experience more health problems compared to well-nourished children. Poor performance among obese scholars could be attributed to low selfesteem, being teased by other scholars among others. It is therefore very crucial for scholars to have normal weight for them to concentrate in the classroom and to attend school regularly.

\section{Auditory short-term memory}

The researcher was required to read a row comprised of letters only at the time to the scholar, see annexure L.
Whereas, the learner was required to remember what was read to him/her and to repeat to the researcher in the same order as was said to him/her in order to move to another level. However, if learner was unsuccessful complete a level after three attempts, the test was automatically stopped.

The study showed a statistically significant deviation (developmental backlog) for cohort of participants in terms of auditory short-term memory, i.e. all of the participants $(\mathrm{N}=8)$ demonstrated a developmental backlog in terms of auditory short-term memory $(p=$ 0.00001 ). This shows that all sub-groups from the four nutritional status categories (normal, overweight, obese 
and underweight) participants $100 \% \quad(\mathrm{~N}=8)$ demonstrated statistically significant performance below par in terms of auditory short-term memory sub-skills. This shows that scholars from each nutritional status were unable to repeat the letters in the correct sequence to the acceptable level. Thus, regardless of the nutritional status scholars performed below average, this could reflect that nutritional status of scholars may not have the direct influence on their performances as suggested by other studies.

\section{Auditory long-term memory}

The researcher was required to read a short story, slowly with good pronunciations to each scholar, see annexure $\mathrm{J}$. Thereafter, the scholar was to repeat the story to the researcher in no particular order and the researcher ticked the correct words using the score cards.

The study showed statistically significant deviation (performance on or above par) for the cohort of participants in terms of auditory long-term memory ( $p=$ 0.00001 ). Most of the sub-groups of participants $75 \%$ $(n=6)$ from the four nutritional status (e.g. $2=$ overweight, $1=$ obese, $2=$ underweight and $1=$ normal) demonstrated statistically significant on par skills in terms of auditory long-term memory sub-skills. While the least of the participants $25 \% \quad(n=2)$ from normal and obese demonstrated statistically significant below par respectively. Most scholars were able to remember the story read to them, meaning that they had good memory regardless of their nutritional status.

\section{One minute Reading (Word Recognition-reading)}

This test was done individually with the scholar, see annexure $\mathrm{M}$. The time limit for the test was one minute; the scholar was requested to read words horizontally as reading from the book as quickly and correctly as they can. At the end of one minute the researcher indicated with a star the last word the scholar has read. Thereafter, the total number of words read correctly were added together to determine the level of word recognition by the scholar.

The study showed statistically significant deviation (developmental backlog) for cohort of participants in terms of one minute reading, which measures scholars word recognition, i.e. all of the participants $(\mathrm{N}=8)$ demonstrated a developmental backlog in terms of one minute reading (word recognition) $(p=0.00001)$. All subgroups from the four nutritional status categories (normal, overweight, obese and underweight) participants 100\%
$(\mathrm{N}=8)$ demonstrated statistically significant performance below par in terms of visual recognition of words sub-skill i.e. single word reading. This shows that scholars from each nutritional status were unable to recognize and read many words as quickly as they can at the acceptable level. Thus, regardless of the nutritional status scholars performed below average, this could reflect that nutritional status of scholars may not have the direct influence on their performances as suggested by other studies.

\section{Visual discrimination}

The researcher showed a word or a symbol to each scholar at the time and thereafter hidden the word or symbol, see annexure N. Next to each word or symbol shown by the researcher there were five options of which one matched the initial word o symbol. Thereafter, the scholar was required to scan through the word or symbol as shown by the researcher and point the correct one among the five options given.

The study showed statistically significant deviation (developmental backlog) for cohort of participants in terms of visual discrimination, since 5 (2 underweight, 2 obese and 1 normal) out of a cohort of 8 participants demonstrated a developmental backlog in terms of Visual discrimination ( $p=0.04431$ ). The visual discrimination results mirrored the results revealed through auditory sequencing.

All sub-group of participants with obese and underweight BMI demonstrated statistically significant performance below par in terms of auditory sequencing, while only 1 of the normal participants demonstrated statistically significant below par skills in terms of visual discrimination (forms and shapes) sub-skills, both of the overweight participants performed on par. The results for undernourished children were in agreement with the study done by Florence, Asbridge, and Veugelers, (2008) that showed a decreased in attendance, attention and academic performance as well as experiencing more health problems among undernourished children compared to well-nourished children. Poor performance among obese scholars could be due to low self-esteem, being teased by other scholars among others. Thus, is very crucial for scholars to have normal weight for them to concentrate in the classroom and to attend school regularly. Most studies as discussed above showed that undernourished children turned to perform academically below average when compared to well-nourished children. The 8 scholars wrote 5 psychometric tests namely, auditory sequencing, auditory long-term sequencing, auditory short-term sequencing, one minute 
reading (word recognition) and visual discrimination (words and shape discrimination). Only two tests namely, auditory sequencing and visual discrimination that discriminated the performance of scholars in terms of remembering the mixture of words and numbers as well as remembering the words or shapes in comparison to scholars nutritional status. The discriminate value of these results lie therein that both obese and underweight participants deviated statistically significant from normative values in terms of both visual discrimination and auditory sequencing.

The performance of scholars in terms of auditory short-term sequencing and one minute reading in comparison to nutritional status was not discriminated and it did not mirror previous studies as all scholars performed below par despite their differences in terms of nutritional status. In addition, most scholars performed on par in terms of auditory long-term sequencing (whereby the researcher read a story to them and they were supposed to repeat the story to the researcher). The performance of scholars in the five psychometric tests (see annexure A) mirrored the academic performance of scholars in the class room. They both did not show a significant academic performance differences in terms of nutritional status, all scholars performed more or less the same.

\section{Link between routine diet, attention span and scholastic performance among Grade 2 scholars' in circuit one in Khomas region}

The frequency of BMI percentile and the likelihood of scholars giving attention in class shows a weak positive linear correlation, $r(\mathrm{~N}=57)=0.116, p=0.389$. Thus, there is no significant correlation between the frequency of BMI percentile and the likelihood of giving attention in the class. According to Sorhaindo and Feinstein, (2006) students experiencing hunger are more likely to be hyperactive and suspended from school meaning they will have significant attention impairment. In addition, children diagnosed with Attention-deficit-hyperactivity disorder (ADHD) suffer from difficulty in concentrating, sitting still and being quiet and tend to have short attention spans. In this regard, since most scholars' nutritional status was normal (79\%) as above thus could not affect the scholars' attention span in the classroom.

This study showed that there is a significant but negative weak linear correlation between the BMI percentile and the arithmetic sub-skills of scholars, $r$ (57) $=-0.274, p=0.039$. Most studies done on nutrition and academic performance have shown that poor quality diet, lack of micronutrients and current nutritional status have influence on the academic performance of scholars and on mathematics in particular (Florence, Asbridge, and Veugelers, 2008; Halterman et al., 2001 cited in Sorhaindo and Feinstein, 2006 ). However, according to this study most scholars nutritional status was normal but they performed poorly in arithmetic, thus nutritional status cannot have a negative impact on the scholars' academic performance.

The analysis showed that there is no significant correlation between the scholars BMI percentile and reading skills and there is a negative correlation between the scholars BMI percentile and reading skills, $r(57)=-$ $0.025, p=0.851$. Most studies done on nutrition and academic performance have shown that poor quality diet, lack of micronutrients and current nutritional status have influence on the academic performance of scholars,(Florence, Asbridge, and Veugelers, 2008; Halterman et al., 2001 cited in Sorhaindo and Feinstein, 2006 ).

The comparison between BMI percentile and reading sub-skills have yielded more or less the same result as shown. Thus, shows nutritional status have little or no influence on scholars reading sub-skills since most scholars nutritional status was normal and most performed poorly in reading.

There was a significant and a moderate strong linear relationship between the scholars' attention span and the reading skills, $r(57)=0.59, p<0.001$. This basically means that the attention spans of the scholar in class have an influence on the performance of scholars in relation to reading sub-skills. As discussed above $52.7 \%$ scholars showed little or more attention impairment while $47.4 \%$ did not show any attention impairment. This, could be a contributing factor to poor academic performance of scholars in relation to reading sub-skill as shown by the study done by Sorhaindo and Feinstein, (2006) that showed children diagnosed with Attention-deficithyperactivity disorder (ADHD) suffer from difficulty in concentrating, sitting still and being quiet and tend to have short attention spans. This kind of behaviour affects the scholars school performance and interaction with other peers as well as compromise self esteem.

There was a significant and positive linear relationship between the scholars attention span and arithmetic skills, $r(57)=0.34, p=0.009$. This basically means that the attention spans of the scholar in class have an influence on the performance of scholars in relation to arithmetic sub-skills. About $52.7 \%$ scholars showed little or more attention impairment comparing to $47.4 \%$ who did not show any attention impairment. Thus, could be a contributing factor to poor academic performance of scholars in relation to arithmetic sub-skill as shown by the study done by Sorhaindo and Feinstein, (2006) that showed children diagnosed with Attention-deficithyperactivity disorder (ADHD) suffer from difficulty in 
concentrating, sitting still and being quiet and tend to have short attention spans. This kind of behaviour affects the scholars school performance and interaction with other peers as well as compromise self esteem.

\section{DISCUSSION}

The descriptive survey was conducted and five data collection tools were administered. The study population was the grade two scholars from two schools that were selected randomly in Windhoek from circuit one. The first tool was the Teacher Connor scale which was administered by the class teacher with the assistant of the researcher and the assistant researcher for all the participants. The weight and the height of the scholars were collected using the BMI checklist to determine the nutritional status of all the participants. The third tool used was the academic performance checklist where the term marks and continuous assessment marks were recorded for all the participants.

Out of the fifty seven $(\mathrm{N}=57)$ participants, a cohort of eight $(\mathrm{N}=8)$ scholars were selected based on the four categories of nutritional status (e.g. underweight, normal, overweight and obese) whereby two scholars were selected from each category to determine their routine diet using the Focused Food frequency completed by the parents and/or guardian within two weeks, as well as the psychometric tests that was administered by the researcher.

The purpose of this study was to determine and describe the link between routine diet capacity for sustained attention span and scholastic performance among Grade 2 scholars in circuit one in Khomas region. The following research objectives were formulated in order to achieve the overall aim. These objectives are:

\section{Objective 1: Routine diet of Grade 2 scholars}

In order to meet the first objective which was to assess the routine diet of the grade 2 scholars in both schools the focused food frequency questionnaire (FFF) was utilized. The questionnaire was completed by the parents or legal guardian of the 8 scholars' cohorts who were selected based on their nutritional status. The parents or legal guardian completed the questionnaire over the period of two weeks. Thereafter, the average calories taken per day were calculated manually to determine the calories intake per day.

This study confirmed the study done by MOHSS (2004) that showed most scholars (39.3\%) always eat and or drinks something in the morning before they go to school, while $18.8 \%$ never eat and/or drink anything and
$23 \%$ eats and/or drink something only sometimes. The result from this study yield that $50 \%$ of the scholars ate breakfast while the other half $50 \%$ did not eat breakfast on regular basis. However, on the other hand this study could not confirm on who eats most when it comes to gender as indicated by the study done by MOHSS (2004) which indicated that male students are less likely (38.4\%) than female students (40.1\%) to eat and or drink something in the morning before they go to school.

However the findings from the study confirm similar reasons cited in MOHSS (2004). The study reveals that the main reason why scholars did not have breakfast was due to the fact that they did not have time for breakfast $(23.4 \%)$, that they could not eat in the morning (16.7\%), that there is no food at home (13.3\%) and that they do like the food at home (3.4\%), (MOHSS 2004). The study revealed that on average scholars who eat breakfast on regular basis had calories intake higher 8127 in week 1 , 6963 in week 2 compare to scholars who did not eat breakfast on regular basis 5035 in week 1, 4874 in week 2. Additionally, the study revealed that on average scholars whose nutritional statuses was obese and overweight had higher calories intake for both weeks compared to those scholars whose nutritional status was normal and underweight. Moreover, scholars whose nutritional status was overweight both ate breakfast on regular basis and their performance in both arithmetic and reading was average and they both did not have attention impairment. While the scholars whose nutritional status was normal both did not have attention impairment and their academic performance in both reading and arithmetic was average while only one of them used to have breakfast $\mathrm{n}$ regular basis. Among the scholars whose nutritional status was obese one performed academically well compared to the other one who performed below average. Whilst, both the underweight did not eat breakfast on regular basis however one of them academically performed on average and had no attention impairment; while the other one academically performed below average and had significant attention impairment. The performance of scholars in the five psychometric tests done with $\mathrm{N}=8$ scholars (see annexure A) mirrored the academic performance of scholars done with $\mathrm{N}=57$ in the class room, (see figure 4-12). They both did not show a significant academic performance differences in terms of nutritional status, as all scholars performed more or less the same.

\section{Objective 2: Ability for sustained attention in class}

In order to meet the second objective which was to assess the Grade 2 scholars' ability for sustained 
attention in class in circuit one in Khomas region in both schools the Teacher Connor scale was utilized. Initially the questionnaire was supposed to be completed by the class teacher of the scholars' however, they claimed that the questionnaire was too long and it was taking their times thus the researcher and the assistant had to go to the school on a daily basis to interview the teachers on that particular scholar. The raw data was entered and analyzed using SPSS 20.0 to determine the attention span of the scholars. Conclusions: this study showed that a total of $52.7 \%$ scholars showed little or more attention impairment comparing to $47.4 \%$ who did not show any attention impairment. In this regard, this study did not reflect the study done by Florence, Asbridge, and Veugelers, (2008) that revealed undernourished children have shown to have decreased attendance in school and attention span thus in turn it means if scholars have normal weight their attendance and attention span in schools was supposed to be excellent. However, is not the case with this study, although most scholars have normal weight, most of them $52.7 \%$ had little or more attention impairment. Moreover, another study has shown that children who do not eat breakfast are more likely to do poorly on schoolwork, have decreased attention span, and have more behavioral problems than their peers who do eat breakfast (AL-Oboudi, 2010). The findings from the 8 sub-groups in Chapter 4 revealed that most scholars (50\%) have breakfast on regular basis thus in turn the scholars were supposed to be attentive in class. To conclude this means that if the scholars are eating breakfast every morning this will assist them to perform well academically, to attend classes as well as to have full attention in class as they will have enough glucose to keep them awake throughout the day. However, this is not the case with this study, since $52.7 \%$ of scholars have little or more attention span despite the fact that the majority (50\%) have breakfast on regular basis.

\section{Objective 3: •Scholastic performances of Grade 2 scholars'}

In order to meet the third objective which is to determine the scholastic performance of Grade 2 scholars in circuit one in Khomas region in both schools the Performance checklist was utilized which capture the points each scholar scored in both the arithmetic and reading subjects to determine their performance. In addition, the five psychometric tests were done to assess the performance of the 8 sub-sample that was selected from each category of nutritional status namely normal, underweight, obese and overweight. The researcher and the assistant tested all the 8 sub-sample on the five psychometric tests within the same time period the FFFQ was completed. It was concluded that lack of breakfast can lead to poor performance in school and that undernourished children have shown to have decreased attendance, attention and academic performance as well as experiencing more health problems compared to wellnourished children (Florence, Asbridge, and Veugelers, 2008). In addition, the study done among 5200 grade five students in Nova Scotia, Canada on diet quality and school performance demonstrated an association between various indicators of diet quality in relation to academic performance, (Florence, Asbridge, and Veugelers, 2008). Students reporting increased diet quality were significantly less likely to fail the literacy assessment, whereas students in the second and third tertile were $26 \%$ and $41 \%$ less likely to fail the literacy assessment. Whilst, students with an increased fruit and vegetable intake and lower caloric intake of fat were significantly less likely to fail the assessment; while boys were twice as likely to fail their literacy assessment compare to girls. However, this study has shown a different picture to the findings from the scholastic performance and the five psychometric tests done with all sub-groups (the main group $\mathrm{N}=57$; and the subgroup $\mathrm{N}=8$ ) as they all showed poor academic performance despite the majority having a normal weight and having breakfast on regular basis. This implies that nutritional status, eating or not eating breakfast is not the only contributing factors to poor academic performance, scholars could perform poorly because of the number of scholars in a classroom which could compromise the attention given to each scholar and the method or the approach of teaching as well as lack of eating quality diet.

\section{Objective 4- To describe the link between routine diets, attention span and scholastic performance among grade 2 scholars' in circuit one in Khomas region}

In order to meet the fourth objective the following variables were collected the attention span, scholastic performance, the diet of the scholars using the correct data collection tools and they were entered and analyzed using appropriate statistical software. Thereafter the correlation between the variables was determined using Pearson correlation.

Conclusions: the study done by Florence, Asbridge, andVeugelers, (2008) showed that undernourished children have been shown to have decreased attendance, attention and academic performance as well as experiencing more health problems comparing to wellnourished children. However, this study showed a weak linear negative and positive correlation between BMI percentile in comparison to the scholars' current 
nutritional status and the academic performance either in reading or arithmetic skills as well as the ability to sustain attention. However, according to this study despite most scholars nutritional status being normal (see figure 4-5) they performed poorly in both reading and arithmetic as well as in the five psychometric tests, thus nutritional status cannot be one of the contributing factors to poor academic performance as stated in the previous studies.

However, the results from the same analysis showed a strong linear correlation between the ability to sustain attention and the academic performance in both arithmetic and reading (English 2nd). Since Figure 4-6 showed that $52.7 \%$ scholars showed little or more attention impairment comparing to $47.4 \%$ who did not show any attention impairment and majority of this scholars perform poorly in school. The study done by (Afmanand Muller, 2006; Brown, 2005; Bellisle, 2004) mirror this study as it showed that attention deficit can result in impaired academic functioning. In addition, attention deficit could be a contributing factor to poor academic performance of scholars in relation to arithmetic and reading sub-skills as shown by the study done by Sorhaindo and Feinstein, (2006) that showed children diagnosed with Attention-deficit-hyperactivity disorder (ADHD) suffer from difficulty in concentrating, sitting still and being quiet and tend to have short attention spans. This kind of behaviour affects the scholars school performance and interaction with other peers as well as compromise self-esteem.

However, this study did not answer the question, why most scholars (52.7\%) had little or significantattention impairment despite their nutritional status being normally distributed since according to Sorhaindo and Feinstein, (2006) scholars experiencing hunger are more likely to be hyperactive and suspended from school.

\section{RECOMMENDATIONS}

Several recommendations emanated from the study. Possible stakeholders who can act on these recommendations include; Ministry of Health and Social services, Ministry of Education, private companies, civil societies as well as the community at large.

\section{A. Recommendations to Ministry of Health and Social Services (MoHSS)}

- Since malnutrition is associated with diseases and poor academic performance it is the opinion of the researcher that the Nutritional department under Primary Health Care (PHC) within MOHSS should consider all ages for the nutrition programmes since at the moment the focus is mostly on children who are five years and lesser.

- The Nutritional department under PHC within MOHSS should collaborate with Ministry of Education (MoE) to offer nutritional feeding at least to all Primary schools in Namibia. Feeding programme should be available at all Primary schools to give scholars the opportunity to opt to eat or not to eat, rather than not having nutritional food available at school.

- Additionally, the MOHSS can revise school health policy as well as the curriculum in collaboration with the MoE so that it can accommodate the nutritional aspect and ensure that the policy is implemented through training of the school principals, school board members, life skill teachers and the entire school family.

\section{B. Recommendations to Ministry of Education (MoE)}

- The main findings that came out of this study have shown that scholars are performing poorly academically in both arithmetic and reading (English 2nd language). Additionally, the five psychometric tests that were done with the 8 sub-scholars have added value to the normal academic performance as the majority of the scholars also performed poorly in all five tests done with them. Firstly, in collaboration with the MOHSS, MoE can implement school feeding programme in all schools despite the location of the schools to be provided at least twice a day, either during the first break or first thing in the morning as well as at lunch before the scholars leave the school premises.

- Secondly, MoE can look at the following in order to improve the quality of education and to improve the performance of the scholars in Khomas regions circuit one as well as the whole education system in Namibia.

- Policy, guidelines and regulation should be developed in order to facilitate the methods of teaching at schools especially at the primary school level as it is foundation for the child to progress smoothly through all the grades.

- The number of scholars in classroom should be set at the maximum of 30 so that the teacher can be able to give enough and quality attention to each and every child in the classroom.

- The schools need to educate parents and children on how to live a healthy lifestyle that includes proper nutrition by establishing committees that include parents and communities members to promote a healthy school atmosphere by focusing on nutrition and vending policies. In addition, schools can help school aged children develop healthy eating habits by emitting a consistent health message by ensuring that healthy food choices are offered at school. At the same time, school administrators can provide opportunities for staffs to receive education on good nutrition and health in the 
school environment.

- Schools should ensure that only nutritious and appealing foods and beverages are provided in schools in school cafeterias, vending machines, snacks bars, schools stores and other venues that offer food and beverages to scholars.

\section{Recommendations for future research}

- The sample population used for this study was small as the participant's parents voluntarily withdrew from the study. Thus, there is a need to replicate this study with the large group in order to assess if the study will yield the same or different results. This study can be replicated eitherwith the same grades, schools and circuit or different grades, schools, circuit and region

- Additionally, the researcher can add the Connor Parent Rating scale in order to get the view of the parents and validate the data with the Connor Teacher Rating scale. It will also be crucial to do the Focus Food Frequency questionnaire and the five Psychometric tests with all the scholars participating in the study in turn to get a broader view on the larger sample population. In addition, it will be essential to compare scholar's nutritional status, academic performances as well as attention from different circuits within the same region.

\section{REFERENCES}

American Dietetic Association (ADA) (2008). Nutrition and You: Trends http://www.eatright.org/ada/files/Overall_Findings_ADA_Trends_20 08.pdf.

American Dietetic Association (ADA) (2005). Position of the American Dietetic Association. J. of the American Dietetic Association, 105: 266-275.

Adegun J, Ajayi-Vincent O, Alebiosu E (2013). Differences in the nutritional status of young school children from public and private owned primary schools in ekiti state, Nigeria. European Scientific J ,.VOL 9, NO.7.

Afman L, Muller M (2006). Nutrigenomics: From Molecular Nutrition to Prevention of Disease. J. of the American Dietetic Association, 106 (2006): 569-576.

AL-Oboudi LM (2010). Impact of breakfast eating pattern on nutrition status, glucose level, iron status in blood and test grades among upper primary school girls in Riyadh city, Saudi Arabia. Pakistan J. of Nutrition , 106-111.

Anding RH (2010). Nutrition Made Clear. Published lecture series on nutrition. Rice University, Department of Kinesiology.

Arsianoglu S, Mroro G.E, Schmitt J (2008). Early Dietary Intervention with a Mixture of Prebiotic Oligosaccharides Reduces the Incidence of Allergic Manifestations and Infections during the First Two Years of Life. J. of Nutri.138: 1091-1095.

Ashton D (2004). Food advertising and Child Obesity; J. of the Royal Society of Med. 97(2): 51-52

Association AH (2013). About Us: American Heart of Association. Retrieved August 22, 2013 , from American Heart of Association website: http://www.heart.org
Bellisle F (2004). Effects of diet on behaviour and cognition in children British J. of Nutrition, Suppl. 2: S227-S232.

Benton D (2011). Diet, behaviour and cognition in Children. In D. K. Angus, Developing Children's food products (pp. 63-77). UK: Woodhead publishing limited.

Benton D (2004). Role of parents in the determination of the food preferences of children and the development of obesity, Inter. j. of obesity, 28: 858-869

Brink H (2009). Fundamentals of Research methodology for health care professionals. Cape Town: Juta.

Brink H (2006). Fundamentals of Research methodology for health care professionals. Cape Town: Juta.

Brown J (2005). Nutrition Now.4th edition. Belmont, CA: Thomson Wadsworth.

Bryan J, Osendarp S, Hughes D, Calvaresi E, Baghurst K, van Klinken J (2004) Nutrients for cognitive development in school aged children, Nutrition Reviews, 62(8): 295-306

Buijzen M, Valkenburg PM (2003). The effects of television advertising on materialism, parent-child conflict and unhappiness: a review of research, Applied Development Psychology, 24: 437-456

Business dictionary (2013 , July 12). Retrieved July 12, 2013 , from http://www.businessdictionary.com

Chotard S, Conkle J, Mason J (2006). Nutrition information in Namibia: Situation analysis and the way forward. New Orleans, LA: Tulane University, Department of international Health, School of Public Health and Tropical med.

Cooke LJ, Wardle J, Gibson EL, Sapochnik M, Sheilham A, Lawson M (2003). Demogrpahic, Familial and trait predictors of fruit and vegetable consumption by pre-school children, Public Health Nutrition, 7(2): 295-302

Dabone C, Delisle HF, Receveur O (2011 ). Poor nutritional status of school children in urban and prei-urban areas of Quagadougou (Burkina Faso) Nutritional j. 2011, 10;34. Retrieved Oct. 13 , 2011 , from http:www.nutritionj.com/content/10/1/34

DeBusk R (2009). Diet-Related Disease, Nutritional Genomics, and Food and Nutrition Professionals. J. of the American Dietetic Association, 109(3): 410-413.

Duyff RL (2006). American Dietetic Association Complete Food and Nutrition Guide. Hoboken, NJ: Wiley.

Elliott SS, Keim NL, Stern JS, Teff K., Havel PJ (2002). Fructose, Weight Gain, and the Insulin Resistance Syndrome. American J. of Clinical Nutrition, 76: 911-922.

Ferguson L (2009). Nutrigenomics Approaches to Functional Foods. J. of the American Dietetic Association, 109:425-458.

Florence MD, Asbridge M, Veugelers PJ (2008). Diet quality and Academic Perforamance. J. of school health, Vol 78, No 4, 209215.

Food Aafriculture Organization (FAO) (2009). Nutrition country profile: The republic of Zambia. Retrieved August 12, 2013, from Food Insecurity and Vulnerability Information and Mapping Systems: ftp://ftp.fao.org/ag/agn/nutrition/ncp/zmb.pdf

Foster-Powell K., Holt SHA, Brand-Miller JC (2002). International Table of Glycemic Index and Glycemic Load Values. American J. of Clinical Nutrition, 76: 5-56.

Gonzalez-Periz A, Horrillo R, Ferre N (2009). Obesity-Induced Insulin Resistance and Hepatic Steatosis Are Alleviated by Omega 3 Fatty Acids. FASEB J. 23(6): 1946-1957.

Google (2013 , July 12). Retrieved July 12, 2013, from http://www.google.com.na

Grosvenor MB, Smolin LA (2006). Nutrition: Everyday Choice . USA: John Wiley and Sons

Guthrie J, Morton J (2000). Food Sources of Added Sweeteners in the Diets of Americans. J. of the American Dietetic Association, 100: 43-51. 
Halterman JS, Kaczorowski JM, Aligne A, Auinger P, Szilagyi (2001). Iron deficiency and cognitive achievement among school-aged children and adolescents in the United States, Pediatrics, 107(6): 1381-1386

Hubbard D (1997 ). Gender and the Law: The age of consent (part2). Retrieved November 28, 2013, from Legal Assistance Centre: http://www.lac.org.na

Insel P, Turner ER, Ross D (2002). Nutrition . USA : Library of Congress Cataloging in Publication Data .

Janice T, Melinda M (2010). Nutrition for life . San Fransisco : Pearson education

Jentjens RL, Jeukendrup AE (2003). Effects of Pre-Exercise Ingestion of Trehalose, Glactose and Glucose on Subsequent Metabolism and Cycling Performance. European J. of Applied Physiology, 88: $459-465$.

Jupp V (2006).The Sage Dictionary of Social Research Methods.London: Sage.

Lazzeri GP, Pilato V, Giacchi MV (2011). Relationship between 8/9 year old school children BMI, parents' BMI and educational level: A cross sectional survey, Nutritional status 2011, 10:76. Retrieved October 13 , 2011, from http:www..nutritionj.com/10/1/76

McArdle WD, Katch FI, Katch VL (2007). Exercise Physiology: Energy, Nutrition, and Human Performance. 6th ed. Baltimore, MD: Lippincott Williams and Wilkins.

Meyer JS, Quenzer LF (2005). Psychopharmacology: Drugs, Brain and Behavior. Sinauer.

Ministry of Education. (2011). EMIS 15 days statistics. Windhoek: MoE.

Ministry of Education (2010). EMIS education statistics. Windhoek: MoE.

Ministry of Health and Social Services (2012). Landscape analysis to accelerate actions to improve maternal and child nutrition in Namibia. Windhoek, Namibia: MOHSS .

Ministry of Health and Social Services (2008 ). National Policy for School Health. Windhoek: MOHSS.

Ministry of Health and Social Services (2008). Namibia Demographic and Health Survey 2006/07. Windhoek: MOHSS

Ministry of Health and Social Services (2004 ). Report on the Namibia school based student health survey. Windheok: MOHSS .

Muris P (2006). Maladaptive schemas in non-clinical adolescents: relations to perceived parental rearing behaviours, big five personality factors, and psychopathological symptoms. Clinical Psychology and Psychotherapy, 13, 405-413.

Namibia Alliance For Improved Nutrition (2010). Malnutrition in Namibia. Windhoek: NAFIN.

National Planning Commission. (2012). Namibia 2011 Population and Housing Census Preliminary results. Windhoek: National Planning Commision
Raben A, Vasilaras T, Moller C, Astruup A (2002). Sucrose Compared with Artificial Sweeteners: Different Effects on Ad Libitum Food Intake and Body Weight after $10 \mathrm{Wk}$ of Supplementation in Overweight Subjects. American J. of Clinical Nutrition, 76: 721-729.

Shils ME, Olson JA, Shike M (1994). Modern nutrition in health and disease. $8^{\text {th }}$ edition, volume 2. Philadelphia: Lea and Febiger.

Sorhaindo A, Feinstein $L$ (2006). What is the relationship between child nutrition and school outcomes? . London : Centre for research on the wilder benefits of learning.

The free dictionary (2013). Retrieved 08 12, 2013 , from Med. dictionary :http://www.thefreedictionary.com

Thomas D, Elliott EJ (2009). Low Glycaemic Index, or Low Glycaemic Load Diets for Diabetes Mellitus. Cochrane Database of Systematic Reviews. 21 Jan. 2009, (1): CD006296.

Thompson J, Manore M (2010). Nutrition for life. San Fransisco: Pearson education.

Taras H (2005). Nutrition and student perforamance at school. J. of School Health, Vol 75, No 6 , 199-213.

Vocabulary .(2013, July 12). Retrieved July 12, 2013, from https://www. vocabulary.com

Vorster H (2010, August 18). The link between poverty and malnutrition: A South African perspective, Vol 15, No 1. Retrieved August 12, 2013, from http://www.hsag.co.za/index. php/HSAG/ article/view/ 435/482

UNICEF (2013, July 2013). Retrieved July 12, 2013, from http://www. unicef.org

USAID (2013, July 2013). Retrieved July 12, 2013, from http://www. usaid.gov

World Health Organization (2000) Nutrition for Health and development, Geneva: World Health Organization

World Health Organization (2004), Department of Nutrition for Health and Development. lodine status worldwide: WHO global database on iodine deficiency (CD-ROM). Geneva, Switzerland: World Health Organization

Ying C, Fengying Z, Wenjun L, Keyou G, Daxun J, Onis Md (2003). Nutritional status of preschool children in poor rural areas of China, Vol 27. China: WHO Bulletin. 